\title{
A Role of Lamin A/C in Preventing Neuromuscular Junction Decline in Mice
}

\author{
Nannan Gao, ${ }^{1 \star}$ Kai Zhao, ${ }^{1,2 *}{ }^{\odot}$ Yu Cao, ${ }^{2}$ Xiao Ren, ${ }^{1}{ }^{\odot}$ Hongyang Jing, ${ }^{1}$ Guanglin Xing, ${ }^{1}$ Wen-Cheng Xiong, ${ }^{1,3}$ and \\ ${ }^{(-1)}$ Lin $\mathrm{Mei}^{1,3}$ \\ ${ }^{1}$ Department of Neurosciences, School of Medicine, Case Western Reserve University, Cleveland, Ohio 44106, ${ }^{2}$ Department of Neuroscience and \\ Regenerative Medicine, Medical College of Georgia, Augusta University, Augusta, Georgia 30912, and ${ }^{3}$ Louis Stokes Cleveland Veterans Affairs \\ Medical Center, Cleveland, Ohio 44106
}

During aging, skeletal muscles become atrophic and lose contractile force. Aging can also impact the neuromuscular junction (NMJ), a synapse that transmits signals from motoneurons to muscle fibers to control muscle contraction. However, in contrast to muscle aging that has been studied extensively, less is known about the molecular mechanisms of NMJ aging although its structure and function are impaired in aged animals. To this end, we performed RNA sequencing (RNA-seq) analysis to identify genes whose expression in synapse-rich region is altered. Gene ontology (GO) analysis highlighted genes relating to nuclear structure or function. In particular, lamin $\mathrm{A} / \mathrm{C}$, an intermediate filament protein critical for the interphase nuclear architecture, was reduced. Remarkably, mutation of lamin $\mathrm{A} / \mathrm{C}$ in muscles or motoneurons had no effect on NMJ formation in either sex of mice, but the muscle mutation caused progressive denervation, acetylcholine receptor (AChR) cluster fragmentation, and neuromuscular dysfunction. Interestingly, rapsyn, a protein critical to AChR clustering, was reduced in mutant muscle cells; and expressing rapsyn in muscles attenuated NMJ deficits of HSA-Lmna-/- mice. These results reveal a role of lamin $\mathrm{A} / \mathrm{C}$ in NMJ maintenance and suggest that nuclear dysfunction or deficiency may contribute to NMJ deficits in aged muscles.

Key words: aging; lamin A/C; neuromuscular junction; rapsyn

\section{Significance Statement}

This study provides evidence that lamin $\mathrm{A} / \mathrm{C}$, a scaffolding component of the nuclear envelope, is critical to maintaining the NMJ in mice. Its muscle-specific mutation led to progressive NMJ degeneration in vivo. We showed that the mutation reduced the level of rapsyn, a protein necessary for acetylcholine receptor (AChR) clustering; and expression of rapsyn in muscles attenuated NMJ deficits of HSA-Lmna-I- mice. These results reveal a role of lamin A/C in NMJ maintenance and suggest that nuclear dysfunction or deficiency may contribute to NMJ deficits in aged muscles.

\section{Introduction}

The neuromuscular junction (NMJ) is a cholinergic synapse between motoneurons and skeletal muscles that controls muscle contraction (Sanes and Lichtman, 2001; Wu et al., 2010; Li et al., 2018). NMJ formation and maintenance are tightly regulated

Received Feb. 24, 2020; revised Aug. 10, 2020; accepted Aug. 11, 2020.

Author contributions: N.G., K.Z., and L.M. designed research; N.G., K.Z., Y.C., H.J., and G.X. performed research; H.J., G.X., W.-C.X., and L.M. contributed unpublished reagents/analytic tools; N.G., K.Z., X.R., H.J., and G.X. analyzed data; N.G. and L.M. wrote the paper.

${ }^{*} N$.G. and K.Z. contributed equally to this work.

This work was supported by the National Institute on Aging Grant AG051510 (to L.M.). We thank Dr. Yixian Zheng (Department of Embryology, Carnegie Science) for providing us the $L m n a^{\text {floxflox }}$ mice, Heath L. Robinson for proofreading and revising grammatical errors in the manuscript, and members of the Mei and Xiong Lab for critical comments and constructive discussions.

The authors declare no competing financial interests.

Correspondence should be addressed to Lin Mei at lin.mei@case.edu.

https://doi.org/10.1523/JNEUROSCI.0443-20.2020

Copyright $\odot 2020$ the authors during development (Li et al., 2018). Impaired functions or mutations of genes critical to NMJ formation have been implicated in various disorders including myasthenia gravis, congenital myasthenic syndrome, and spinal muscular atrophy. Considerable evidence suggests NMJs decline during aging in leg muscles including tibialis anterior (TA) and extensor digitorum longus (EDL; Grimby and Saltin, 1983; Doherty et al., 1993; Roos et al., 1997; Deschenes et al., 2010; Valdez et al., 2010). In mice 22 months old (M) or older, acetylcholine receptor (AChR) clusters are fragmented and cluster total areas are reduced (BaliceGordon, 1997; Messi and Delbono, 2003; Valdez et al., 2010; Li et al., 2011; Zhao et al., 2018). In mice $24 \mathrm{M}$ or older, many clusters are poorly innervated (Valdez et al., 2010; Chai et al., 2011; Zhao et al., 2018) or innervated by multiple axons (Valdez et al., 2010; Samuel et al., 2012), and varicosities appear in nerve endings of motoneurons (Valdez et al., 2010; Chai et al., 2011). Impaired NMJ transmission [reduced compound muscle action potential (CMAP) and miniature endplate potential (mEPP) amplitude] 
was noted in gastrocnemius (GA) muscles and diaphragms of 24 M mice, compared with $3 \mathrm{M}$ mice (Zhao et al., 2018), although no difference was observed between 12 and $26 \mathrm{M}$ mice in another report (Willadt et al., 2016).

NMJ development and maintenance require interactions between motoneurons, muscle fibers, and Schwann cells (Sanes and Lichtman, 2001; Wu et al., 2010; Li et al., 2018). Noticeably, agrin-LRP4-MuSK signaling is critical (DeChiara et al., 1996; Gautam et al., 1996; Hesser et al., 2006; Weatherbee et al., 2006; Chevessier et al., 2008; Kim et al., 2008; Zhang et al., 2008; Samuel et al., 2012; Zong et al., 2012; Barik et al., 2014). The intracellular protein rapsyn (receptor-associated protein at the synapse) is also necessary, likely by serving as an anchor for AChRs (Burden et al., 1983; Walker et al., 1984; LaRochelle and Froehner, 1986; Apel et al., 1995; Gautam et al., 1995) and/or as an E3 ligase to regulate proteins by posttranslational modification including neddylation ( $\mathrm{Li}$ et al., 2016). Moreover, rapsyn turns over with a half-life of several hours in muscle cells and its stability requires $\mathrm{Hsp} 90 \beta$ (Luo et al., 2008). Muscle fibers contain many nuclei; however, only those beneath the NMJ are active in transcribing genes for NMJ structure and function (Merlie and Sanes, 1985; Meier et al., 1997; Schaeffer et al., 2001; Wu et al., 2010; Li et al., 2018).

To investigate pathologic mechanisms in NMJ aging, we compared mRNAs enriched in the synaptic region (SR) between young adult and aged mice. Gene ontology (GO) analysis highlighted changes in genes involved in nuclear structure or function. In particular, lamin $\mathrm{A} / \mathrm{C}$, an intermediate filament that is critical for the interphase nuclear architecture (Hutchison, 2002; Mounkes et al., 2003; Burke and Stewart, 2006, 2013), was reduced in aged muscles. The mutations of lamin A/C are implicated in premature aging disorders (De Sandre-Giovannoli et al., 2003; Broers et al., 2006; Scaffidi and Misteli, 2006). Indeed, NMJ deficits were observed in germline Lmna mutant mice (Lmna-/-; Méjat et al., 2009). However, because of its ubiquitous expression, Lmna-/- mice display deficits in multiple tissues such as cardiomyopathy (Sullivan et al., 1999) and axonopathy (De Sandre-Giovannoli et al., 2002), making it unclear whether the NMJ deficits are because of the lack of lamin A/C in motoneurons and/or muscles, or occur as compensatory mechanisms. We addressed this important question here by cellspecific mutation and determination of onset times of NMJ and muscle deficits. Muscle-specific Lmna mutant mice, but not the motoneuron-specific Lmna mutant, demonstrated progressive deficits in NMJ morphology and transmission. We investigated how lamin A/C mutation impacts AChR clusters in vivo and agrin-LRP4-MuSK signaling. We show that rapsyn was decreased in Lmna mutant muscles, and expressing rapsyn mitigated NMJ deficits in the mutant mice. Our results support a model in which muscle lamin A/C maintains $\mathrm{NMJ}$ integrity and transmission by maintaining rapsyn level.

\section{Materials and Methods}

Mouse lines and genotyping

Lmna ${ }^{f / f}$ mice (Kim and Zheng, 2013) were kindly provided by Yixian Zheng (Department of Embryology, Carnegie Science); HSA-Cre mice (Miniou et al., 1999), HB9-Cre mice (Arber et al., 1999; Yang et al., 2001), and Ai9 mice (Madisen et al., 2010) were described previously and purchased from The Jackson Laboratory (HSA-Cre: stock \#006149; HB9-Cre: stock\# 006600; Ai9: stock \#007909). Offspring were screened for the correct genotype by PCR for genomic DNA from the tail. Three, 12 , and $24 \mathrm{M}$ mice were acquired from the National Institute on Aging. Mice were backcrossed into C57BL/6 background (The Jackson
Laboratory, stock \#000664) and housed in a room with a 12/12 h light/ dark cycle and have free access to water and rodent chow diet. Both genders were used in the study and the Institutional Animal Care and Use Committee (IACUC) of Case Western Reserve University approved all experiments.

\section{Reagents and antibodies}

Chemicals were purchased from Sigma-Aldrich unless otherwise indicated. CF568 conjugated $\alpha$-bungarotoxin ( $\alpha$-BTX) was purchased from Biotium (\#00006; 1:500 for staining). Primary antibodies used were as follows: lamin A/C (1:500 for Western blotting, 1:400 for immunostaining; 3A6-4C11, Active Motif), glyceraldehyde 3-phosphate dehydrogenase (GAPDH; 1:3000 for Western blotting; NB600-501, Novus), LAP2 (1:500 for Western blotting; ab5162, Abcam), HP1 (1:500 for Western blotting; sc-515341, Santa Cruz Biotechnology), Tri-Me-H3K9 (1:1000 for Western blotting; ab8898, Abcam), $\gamma \mathrm{H} 2 \mathrm{AX}$ (1:500 for Western blotting; sc-517348, Santa Cruz Biotechnology), histone H3 (1:500 for Western blotting; sc-517576, Santa Cruz Biotechnology), ChAT (1:50 for staining; AB144P, Millipore Sigma), neurofilament (NF; 1:500 for staining; C28E10, Cell Signaling Technology) and synapsin-1 (Syn; 1:500 for staining; D12G5, Cell Signaling Technology), laminin (1:200 for staining; L9393-041M4799, Sigma-Aldrich), AChR $\delta$ (1:2000 for Western blotting; 88B, ThermoFisher Scientific), $\mathrm{AChR} \beta$ (1:1000 for Western blotting; sc-11371, Santa Cruz Biotechnology), laminin $\beta 2$ (1:1000 for Western blotting; PA5-103211, ThermoFisher Scientific), and AChE (1:500 for Western blotting; sc-373901, Santa Cruz Biotechnology). Anti-rapsyn, anti-LRP4, and anti-MuSK antibodies were described previously (1:1000 for Western blotting; Luo et al., 2008; Zhang et al., 2008; Shen et al., 2013; Barik et al., 2014; Zhao et al., 2017). Secondary antibodies used were as follows: Alexa Fluor 488 anti-rabbit IgG (A-11008), Alexa Fluor 488 anti-mouse IgG (A-11001), Alexa Fluor 488 anti-goat IgG (A-11055), Alexa Fluor 594 anti-rabbit IgG (A-11012), and Alexa Fluor 647 anti-mouse IgG (A-21235) antibodies (1:500 for staining) are from Invitrogen; horseradish peroxidase (HRP)-conjugated goat antirabbit IgG (ab205718) and HRP-conjugated goat anti-mouse IgG (ab205719) antibodies (1:5000 for Western blotting) are from Abcam.

RNA sequencing (RNA-seq)

Total RNA from the SR was obtained using RNeasy Mini kit (QIAGEN, 74104) according to the manufacturer's instructions. The library preparation and RNA-seq were commercially commissioned to Georgia Cancer Center at Augusta University. The data were generated by Hiseq2500 through NGS in fast mode as single end. After sequencing was completed, configureBclToFastq.pl, a Perl script from illumina, was run to get reads data in FASTQ format. Then we used HISTA2 to map reads against UCSC mm10 mouse reference transcript and genome (Kim et al., 2015). We counted each sample's reads mapped to each gene of $\mathrm{mm} 10$, and got the result of differentially expressed (DE) genes through edgeR package (dispersion $=0.04$, other parameters used as default; Robinson et al., 2010). DE genes were identified by applying a $p$ value cutoff of 0.05 and a fold change (FC) of 1.5. The expression profile heatmap of DE genes was generated using ggplot2 package in $\mathrm{R}$ (Wickham, 2016). GO analysis of DE genes is conducted by ClusterProfile package in $R$ (vision 3.5; Yu et al., 2012).

\section{Immunohistochemistry}

For NMJ staining, whole-mount diaphragms and TA muscle fibers were stained as previously described (Dong et al., 2006; Li et al., 2008; Zhao et al., 2018). Briefly, entire diaphragms with ribs or muscles were fixed in $4 \%$ paraformaldehyde (PFA) in $0.1 \mathrm{~m}$ phosphate buffer $(\mathrm{PB})$ at $4^{\circ} \mathrm{C}$ for $48 \mathrm{~h}$, rinsed three times with PBS ( $\mathrm{pH} 7.4$ ), and incubated with $0.1 \mathrm{M}$ glycine in $\mathrm{PBS}$ for $1 \mathrm{~h}$ at room temperature. Tissues were incubated overnight at $4^{\circ} \mathrm{C}$ with primary antibodies against NF and Syn in the blocking buffer ( $10 \%$ goat serum and $2 \%$ Triton X-100 in PBS). After washing four times for $20 \mathrm{~min}$ each with $2 \%$ Triton X-100 in PBS, tissues were incubated with Alexa Fluor 488-conjugated or Alexa Fluor 647-conjugated secondary antibody (1:500) and CF568-conjugated $\alpha$-BTX (1:500) for $2 \mathrm{~h}$ at room temperature. After washing four times for $20 \mathrm{~min}$ each with $2 \%$ Triton X-100 in PBS, tissues were mounted in VECTASHIELD 


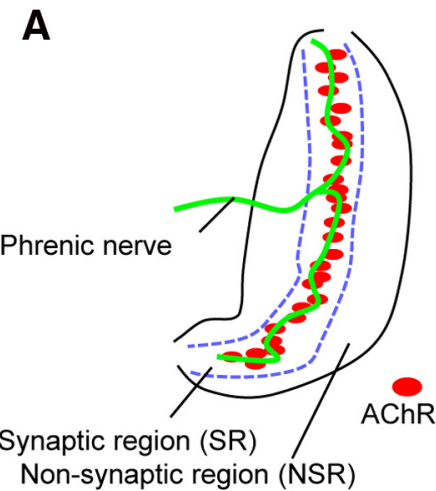

D

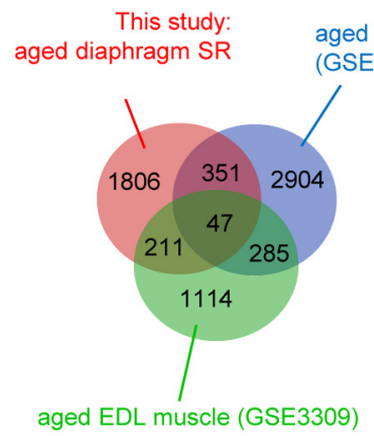

B

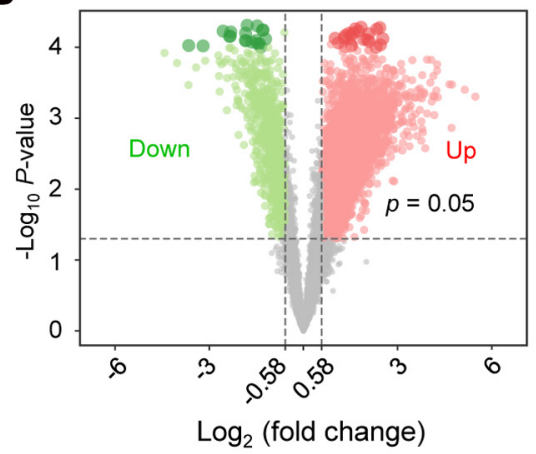

E cellular components

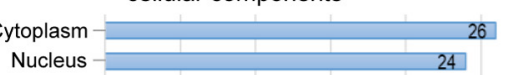

Membrane -22

Nucleoplasm - 11

Cytosol - 10

Mitochondrion - 10

Perinuclear region of cytoplasm -

Cytoplasmic vesicle -5

Dendrite 4

Nuclear membrane - 4

Myelin sheath -4

Mitochondrial outer membrane 3

$Z$ disc - 3

Microvillus 3

Basal plasma membrane -2

Sarcoplasmic reticulum membrane -2

Pseuxdopodium -
C

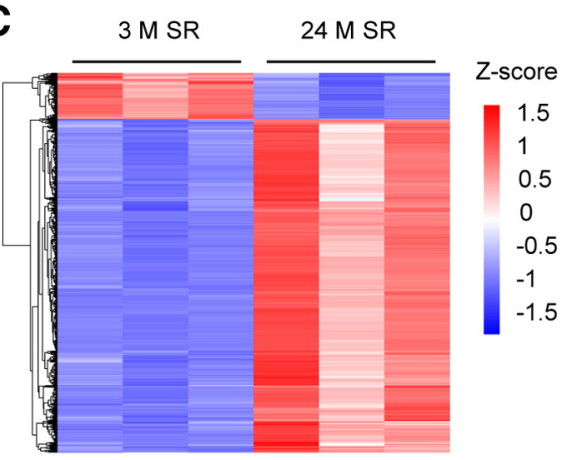

$\mathbf{F}$

\begin{tabular}{|c|c|c|c|}
\hline \multicolumn{4}{|c|}{ Gene symbol } \\
\hline Odc1 & Gsto1 & Fdps & Erffi \\
\hline Nos1 & Lmna & Sord & Pim1 \\
\hline Mrpl38 & Jph2 & Timeless & Map2k2 \\
\hline Rab11b & Ptov1 & Pkn1 & Speg \\
\hline Ldb3 & Bad & Mrpl44 & Cnp \\
\hline Tnk2 & Atf3 & Rapgef3 & Notch4 \\
\hline Pdgfa & Plec & Fabp5 & Rgs4 \\
\hline Cnn3 & Samd4b & Cct3 & Spry1 \\
\hline Id1 & Foxk2 & Cebpd & Dlst \\
\hline Igfbp5 & Wsb2 & Lemd2 & Tufm \\
\hline Mfhas1 & Tcf3 & Klf4 & Pmepa1 \\
\hline Arntl & Gnai2 & Gde1 & \\
\hline
\end{tabular}

G

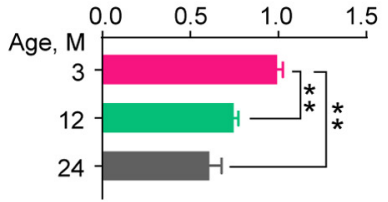

H

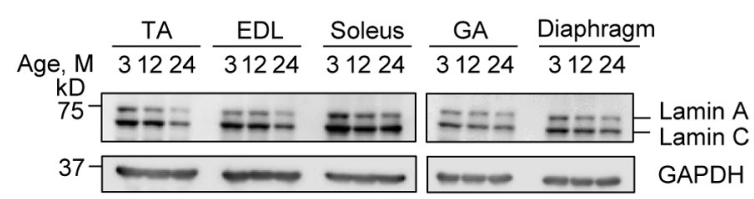

I

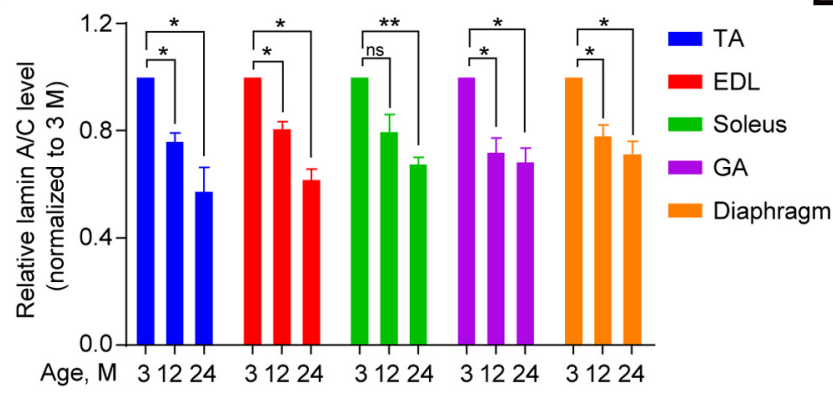

J

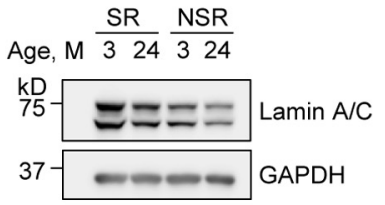

$\mathbf{L}$

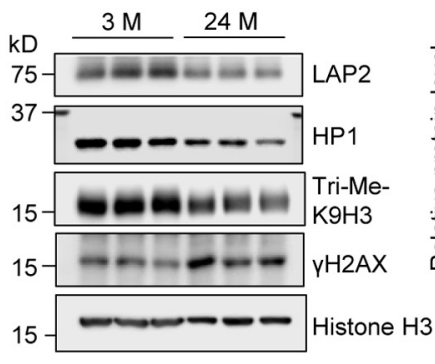

M
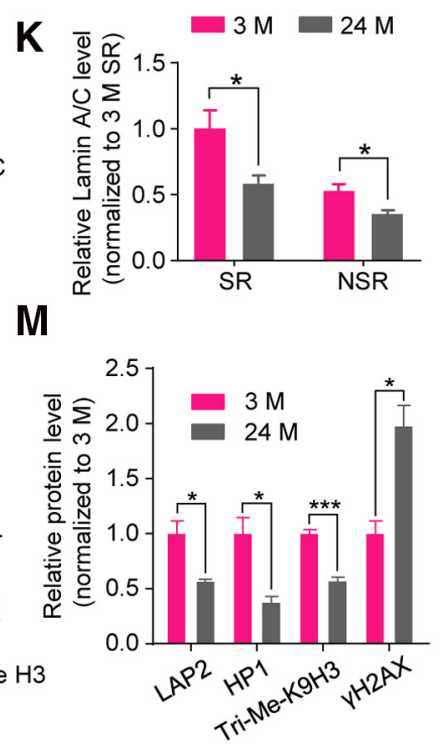

Figure 1. Abnormal expression of nuclear proteins in aged mice. $A$, Schematic diagram of mouse diaphragm. NSR, non-SR. Green line indicates nerve terminals and red patches represent AChR clusters. B, Volcano plot for DE genes (2415 downregulated, in green; 2621 upregulated, in red) in $24 \mathrm{M}$ diaphragm SR samples compared with samples from $3 \mathrm{M}$ mice. Green and red dots indicated statistical DE genes. C, Heatmap of DE genes in $24 \mathrm{M}$ SR samples compared with that from $3 \mathrm{M}$ mice. Each row of the heatmap represents the $z$ score transformed log 2 $(1+F P K M)$ values of one DE gene across samples (blue, low expression; red, high expression). $\boldsymbol{D}$, Venn diagrams of downregulated genes in this study and other aged muscle DE datasets, illustrating overlapped decreased genes (47 genes) among three datasets. $\boldsymbol{E}, G 0$ enrichment analysis of overlapped genes in $\boldsymbol{D}$. Downregulated genes in aged mice were enriched in cellular components including "nucleus," "nucleoplasm," and "nuclear membrane." $\boldsymbol{F}$, List of overlapped genes in $\boldsymbol{D}$. $\boldsymbol{G}$, Reduced mRNA level of $L$ mna determined by real-time PCR for TA muscle from 12 and $24 \mathrm{M}$ mice compared with $3 \mathrm{M}$. Data were shown as mean \pm SEM 3 versus $12 \mathrm{M}, t_{(4)}=7.973,{ }^{* *} p=0.0013 ; 3$ versus $24 \mathrm{M}, t_{(4)}=5.724,{ }^{* *} p=0.0046$. Unpaired $t$ test, $n=3$ mice per group. $\boldsymbol{H}$, Decreased lamin $\mathrm{A} / \mathrm{C}$ protein level in muscles from 12 and $24 \mathrm{M}$ mice compared with $3 \mathrm{M}$. $\boldsymbol{I}$, Quantitative analysis for data in $\boldsymbol{H}$. Data were shown as mean \pm SEM TA, $t_{(2)}=7.974$, ${ }^{*} p=0.0154$ for $12 \mathrm{M}, t_{(2)}=4.772,{ }^{*} p=0.0412$ for $24 \mathrm{M}$; EDL, $t_{(2)}=7.435,{ }^{*} p=0.0176$ for $12 \mathrm{M}, t_{(2)}=9.819,{ }^{*} p=0.0102$ for $24 \mathrm{M}$; solues, $t_{(2)}=3.212, p=0.0848$ for $12 \mathrm{M}, t_{(2)}=14.68$, ${ }^{* *} p=0.0046$ for $24 \mathrm{M} ; \mathrm{GA}, t_{(2)}=5.439,{ }^{*} p=0.0322$ for $12 \mathrm{M}, t_{(2)}=5.986,{ }^{*} p=0.0268$ for $24 \mathrm{M}$; diaphragm, $t_{(2)}=5.757,{ }^{*} p=0.0289$ for $12 \mathrm{M}, t_{(2)}=6.224,{ }^{*} p=0.0249$ for $24 \mathrm{M}$. Paired $t$ test, $n=3$ mice per group. J, Decreased lamin A/C protein in SR and NSR from $24 \mathrm{M}$ diaphragm versus $3 \mathbf{M}$. $\boldsymbol{K}$, Quantification for data in $\boldsymbol{J}$ indicated lamin A/C declined more in SR (average of $47 \pm 15 \%$ ) than in NSR (average of $22 \pm 7 \%$ ) in aged muscles. Data were shown as mean \pm SEM $t_{(4)}=2.805,{ }^{*} p=0.0486$ for SR; $t_{(4)}=2.818,{ }^{*} p=0.0479$ for NSR, unpaired $t$ test, $n=3$ 
mounting medium (H-1700, Vector Laboratories) and covered with a coverslip. For cross-sections staining of muscles, muscles were fixed with $4 \%$ $\mathrm{PFA}$ in $\mathrm{PB}$ at $4^{\circ} \mathrm{C}$ overnight and fully dehydrated in $30 \%$ sucrose at $4^{\circ} \mathrm{C}$. Then $25-\mu \mathrm{m}$ sections were cut with a cryostat (HM550, ThermoFisher Scientific). Sections were incubated with the blocking buffer for $1 \mathrm{~h}$ at room temperature and then with primary antibodies at $4^{\circ} \mathrm{C}$ for $48 \mathrm{~h}$. After washing three times for $10 \mathrm{~min}$ each with $0.5 \%$ Triton X-100 in PBS, samples were incubated with Alexa Fluor 594-conjugated secondary antibody (1:500) overnight at $4^{\circ} \mathrm{C}$ and mounted with VECTASHIELD mounting medium. For single muscle fiber isolation and immunostaining, EDL muscles with tendons were carefully dissected and digested with collagenase II $(400 \mathrm{U} / \mathrm{ml})$ in DMEM at $37^{\circ} \mathrm{C}$ for $1 \mathrm{~h}$. Digested muscles were fixed with $4 \%$ PFA for $5 \mathrm{~min}$ at room temperature and gently washed twice with PBS. Muscles were gently triturated using a fire-polished glass Pasteur pipette to release individual muscle fibers. Under a microscope, straight and intact muscle fibers were selected and transferred onto coverslips and subjected to immunostaining. Muscle fibers were incubated with $2 \%$ Triton X-100 in PBS for $30 \mathrm{~min}$ and with the blocking buffer for $1 \mathrm{~h}$ at room temperature. Samples were incubated with CF568-conjugated $\alpha$-BTX (1:500) and $4^{\prime}, 6^{\prime}$-diamidino-2-phenylindole dihydrochloride (DAPI; $1: 1000)$ for $2 \mathrm{~h}$ at room temperature, washed, and mounted with VECTASHIELD mounting medium. Z-serial images were collected with a Zeiss confocal laser scanning microscope (LSM 700) and projected into a single image.

\section{Real-time PCR}

Total RNA was isolated using TRIzol reagent (15596018, Invitrogen) and total cDNA was synthesized using a cDNA synthesis kit (GoScript Reverse Transcription System, A5001, Promega). The real-time PCR was performed with SYBR Green qPCR master mix (204056, QIAGEN) in a $20-\mu$ l reaction system on StepOnePlus real-time PCR system (Applied Biosystems) according to the supplied manuals and PCR included an initial step at $95^{\circ} \mathrm{C}$ for $3 \mathrm{~min}$, followed by 40 cycles of denaturation at $95^{\circ} \mathrm{C}$ for $15 \mathrm{~s}$, annealing, and extension at $60^{\circ} \mathrm{C}$ for $60 \mathrm{~s}$. Gapdh was used as an internal control. The primers for individual genes were as follows (F, forward; R, reverse): Lmna, F: 5'-TGTGGCGGTA GAGGAAGTCG-3' and R: 5'-GGAAGCGATAGGTCATCAAAGG-3'; Rapsn, F: $5^{\prime}$-GTGGATGAAGGTGCTGGAGAAG-3' and R: $5^{\prime}$-CCGA GCAGTATCAATCTGGACC-3'; Lrp4, F: $5^{\prime}$-AGTCACCGCAAGGCT GTCATTA-3' and R: $5^{\prime}$-GTTGGCACTATTGATGCTCTTGG-3'; $M u S K$, F: $5^{\prime}$-ACCGTCATCATCTCCATCGTGT-3' and R: 5' -CTCAATGTTA TTCCTCGGATACTCC-3'; Chrnd, F: 5'-GAATGAGGAACAAAGGC TGAR-3' and 5'-GGTGAGACTTAGGGCGACAT-3'; Chrnb, F: 5'TATTCGGCGGAAGCCTCTCTTC-3' and R: $5^{\prime}$-GCAGCAAGAACA CAGTGAGCGT-3'; LAMB2, F: 5'-GAACTTCGCTTGGGCCTACTT-3' and R: 5'-GGTGGCTGGATAGCAGCTT-3'; ITGB1, F: 5' - ATGCCAAA

mice per group. $L$, Compromised nuclear proteins in SR from $24 \mathrm{M}$ diaphragm showed nuclear defects and increased DNA damage in subsynaptic nuclei. $M$, Quantification for data in L. Data were shown as mean \pm SEM $t_{(4)}=3.78,{ }^{*} p=0.0194$ for LAP2; $t_{(4)}=4.006$, ${ }^{*} p=0.0161$ for HP1; $t_{(4)}=9.823,{ }^{* * *} p=0.0006$ for Tri-Me-H3K9; $t_{(4)}=4.564,{ }^{*} p=0.0103$ for $\gamma \mathrm{H} 2 \mathrm{AX}$; unpaired $t$ test, $n=3$ mice per group. ns, no significant difference.
B
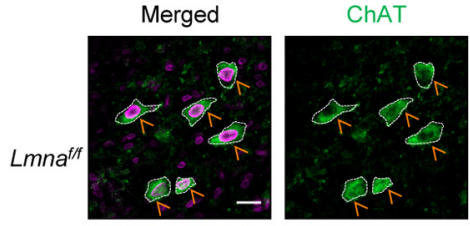

Lamin A/C

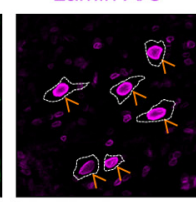

HB9-Lmna-
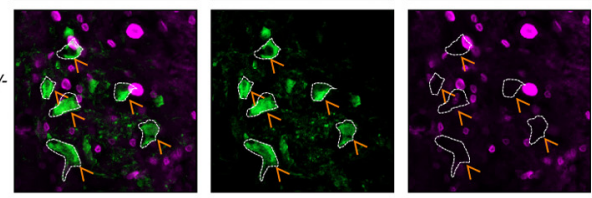

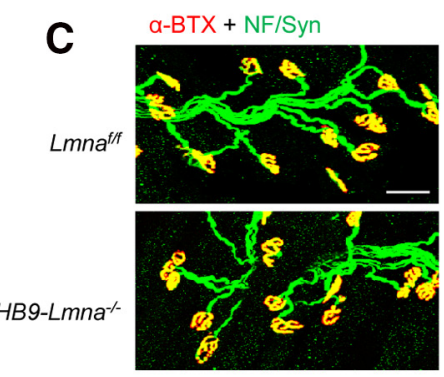

$\mathbf{E}$

$\mathbf{F}$

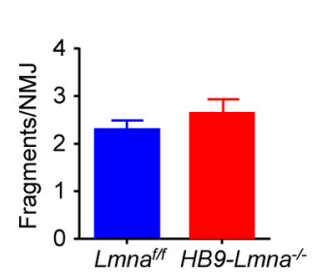

G

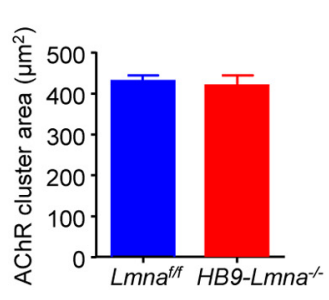

D

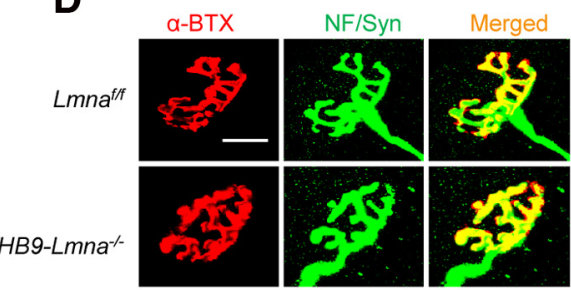

Figure 2. Normal NMJ morphology in adult HB9-Lmna-/- mice. A, Representative images of diaphragm from 2 M HB9::Cre:: Ai9 (HB9-Aig)mouse. Muscles were imaged directly without staining; motor nerves were visibly labeled by td-Tomato signals. Scale bar, $100 \mu \mathrm{m}$. B. Representative images of lumbar sections of spinal cords from $2 \mathrm{M}$ control and HB9-Lmna-1- mice. Spinal cord

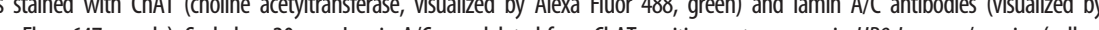
NMJ form muscles of the indicated genotype. Scale bar, $20 \mu \mathrm{m}$. $\boldsymbol{E}-\mathbf{G}$, Quantification of data in $\boldsymbol{C}, \boldsymbol{D}$ showed unaffected NMJ innerva$p=0.6555$ for $\boldsymbol{C} ; t_{(8)}=1.061, p=0.3195$ for $\boldsymbol{D} ; t_{(8)}=0.3450, p=0.7390$ for $\boldsymbol{E}$; unpaired $t$ test, $n=5$ mice per genotype.

TCTTGCGGAGAAT-3' and R: 5' ${ }^{\prime}$-TTTGCTGCGATTGGTGACA TT-3'; ACHE, F: 5'-GGCTCCTACTTTCTGGTTTACGG-3' and R: 5'-GGCTGCCAGGTCACTTGCTT-3'; and Gapdh, F: 5'-AAGG

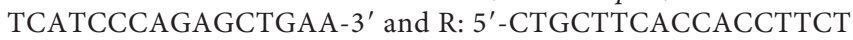
TGA-3'

\section{Western blot assay}

Western blotting was performed as previously described (Dong et al., 2020). Briefly, samples were separated by SDS-PAGE, transferred to nitrocellulose membranes, probed with specific antibodies, and visualized with enhanced chemiluminescence (32106, Thermo Scientific). Immunoreactive bands were imaged using the LI-COR Odyssey Fc imaging system. For examination of specific protein levels, tissues and cells were homogenized in modified RIPA buffer [ $150 \mathrm{~mm} \mathrm{NaCl}, 50 \mathrm{~mm}$ Tris- $\mathrm{HCl}$ (pH 7.4), 2 mм EDTA, $1 \%$ SDS, $0.5 \%$ Triton X-100, 20\% glycerol, $1 \mathrm{~mm}$ phenylmethylsulfonyl fluoride (PMSF), $5 \mathrm{~mm} \mathrm{NaF}, 2 \mathrm{~mm} \mathrm{Na}_{3} \mathrm{VO}_{4}$, and cOmplete protease inhibitor (4693132001, Roche)]. Samples were then centrifuged at $12,000 \times g$ for $10 \mathrm{~min}$ at $4^{\circ} \mathrm{C}$ to remove debris. Protein concentration was determined by Pierce BCA Protein Assay kit (23225, Thermo Scientific), an equal volume of $2 \times$ SDS sample buffer was added to denature proteins. Approximately $50 \mu \mathrm{g}$ of protein were subjected to Western blotting. 
A
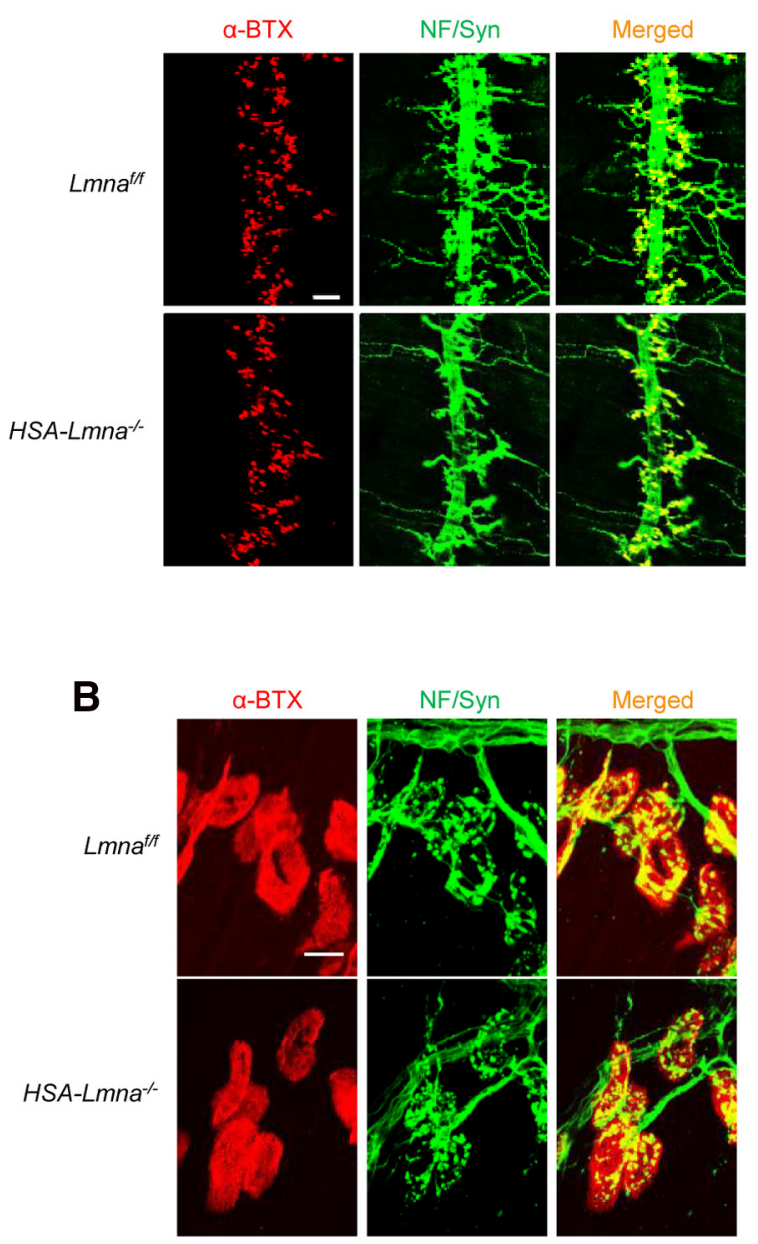

E

C
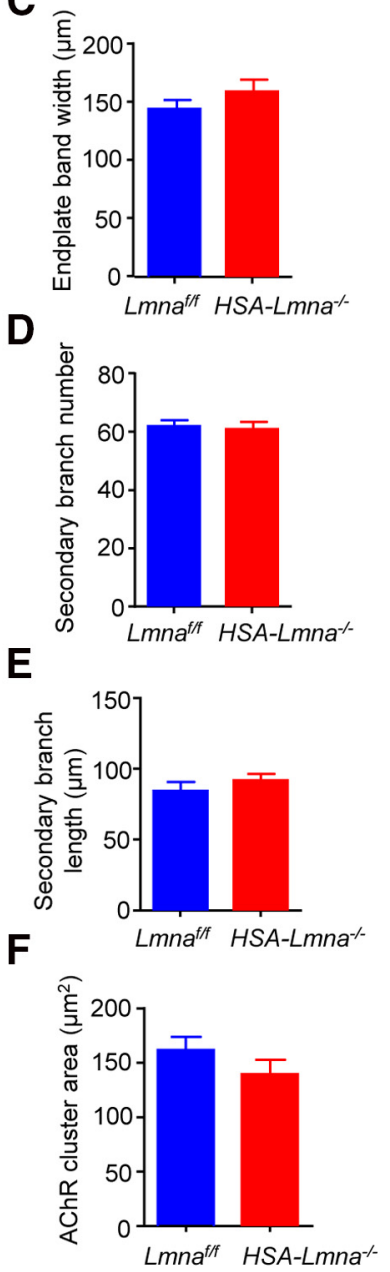

Figure 3. Normal neonatal NMJ in HSA-Lmna-/- mice. $\boldsymbol{A}, \boldsymbol{B}$, NMJ morphologies were comparable between control and HSA-Lmna- / - mice at P0. Whole-mount diaphragms were stained with CF568 $\alpha$-BTX (red) to label AChR clusters and with anti-NF/Syn antibodies (visualized by Alexa Fluor 488, green) to label motor nerve terminals. $A$, Representative images for the ventral region of the left diaphragms from control and mutant mice at low magnification. Scale bar, $100 \mu \mathrm{m} . \boldsymbol{B}$, Enlarged images of individual AChRs and motor nerve terminals from diaphragms of indicated genotypes. Scale bar, $10 \mu \mathrm{m}$. $\boldsymbol{C}-\boldsymbol{F}$, Quantitative data of endplate band width $(\boldsymbol{C})$, secondary branch number $(\boldsymbol{D})$, secondary branch length $(\boldsymbol{E})$, and $\mathrm{AChR}$ cluster area $(\boldsymbol{F})$ of control and mutant mice. Data were shown as mean $\pm \mathrm{SEM}, t_{(8)}=1.143, p=0.2859$ for $\boldsymbol{C}_{;} t_{(8)}=0$. 3847, $p=0.7105$ for $\boldsymbol{D} ; t_{(8)}=0.9726, p=0.3592$ for $\boldsymbol{E}_{;} t_{(8)}=1.324, p=0.2222$ for $\boldsymbol{F}$; unpaired $t$ test, $n=5$ mice per genotype.

\section{Electrophysiological recording}

Eectrophysiological recording of CMAPs was performed as described previously (Li et al., 2016; Zhao et al., 2017). Mice were anesthetized using ketamine and xylazine mixture (100 and $10 \mathrm{mg} / \mathrm{kg}$ body weight, respectively) and then put on a $37^{\circ} \mathrm{C}$ heating pad. The stimulation needle electrode (TECA, 092-DMF25-S) was inserted near the sciatic nerve at thigh level of the left leg and connected to an isolator (ISO-Flex, AMPI). The reference needle electrode was inserted into the Achilles tendon and the recording needle electrode was inserted into the middle of left GA, both of which were connected to AxoPatch 200B Amplifier (Molecular Devices). The sciatic nerve was stimulated with a series of 10 stimuli at $1,5,10,20$, and $40 \mathrm{~Hz}$ and was CMAP recorded by Digidata $1322 \mathrm{~A}$ and analyzed by Clampfit 9.2 software (Molecular Devices).

For mEPPs recording, left hemidiaphragm were dissected with ribs and phrenic nerves were quickly dissected from euthanized mice, mounted onto Sylgard gel and merged in fully oxygenated $\left(95 \% \mathrm{O}_{2}, 5 \%\right.$ $\mathrm{CO}_{2}$ ) Ringer solution ( $137 \mathrm{~mm} \mathrm{NaCl}, 5 \mathrm{~mm} \mathrm{KCl}, 12 \mathrm{~mm} \mathrm{NaHCO}_{3}, 1 \mathrm{~mm}$ $\mathrm{NaH}_{2} \mathrm{PO}_{4}, 1 \mathrm{~mm} \mathrm{MgCl}, 2 \mathrm{~mm} \mathrm{CaCl}$, and $11 \mathrm{~mm}$ D-glucose; $\mathrm{pH}$ 7.3) at room temperature. To record mEPPs, microelectrodes (CV203 BU
HEADSTAGE, 20-40 m $\Omega$, filled with $3 \mathrm{~m} \mathrm{KCl}$ ) connected to the AxoPatch 200B Amplifier was inserted to central regions of the muscle. Recordings were performed when resting membrane potentials were at $-65-75 \mathrm{mV}$. Five recordings (for 2-3 min each) were performed per diaphragm. Data were collected with AxoPatch 200B Amplifier and Digidata 1322A $(10-\mathrm{kHz}$ low-pass filtered) and analyzed by Clampfit 9.2 software.

Experimental design and statistical analysis All data were generated by at least three replicates from independently prepared samples, and the total number of mice or tissues used per group was provided in the figure legends. Both genders were used and 10-30 NMJs or muscle fibers were quantified for each mouse. The sample size $(n)$ was based on the literature (Wu et al., 2012b; Shen et al., 2013; Barik et al., 2014; Zhao et al., 2017). Data were analyzed by unpaired $t$ test, one-way ANOVA (with Tukey's multiple comparison test) and two-way ANOVA (with Bonferroni's post hoc test). GraphPad Prism (version 6, GraphPad Software) was used for statistical analysis. Data are shown as mean \pm SEM. Statistical difference was considered when $p<0.05$. The $p$ values were presented as ${ }^{*} p<0.05,{ }^{* *} p<0.01,{ }^{* *} p<0.001$. ns, no significant difference.

\section{Results}

\section{Abnormal expression of nuclear} proteins in muscular SR of aged mice

To identify genes that are critical to NMJ formation/maintenance and whose expression is altered in aged mice, we isolated SRs of diaphragms (Fig. 1A) and performed RNA-seq analysis of SR samples from 3 and $24 \mathrm{M} \mathrm{C57BL/6}$ mice. A total of 5036 DE genes were identified with the filter of $\mathrm{FC} \geq 1.5$ and $p<0.05$ (Fig. $1 B, C$ ). Among them, 2415 were downregulated (Fig. $1 B$, in green) and 2621 were upregulated (Fig. $1 B$, in red). We reasoned that critical molecules in maintaining NMJ structure and function should be reduced in aged muscles and may have been revealed already by datasets in the literature. Therefore, we conducted a cross-comparison between our dataset with published data including aged EDL muscle data in GSE3309 and aged GA muscle data in GSE6323, and identified 47 genes that were reduced in all three datasets (Fig. 1D,F). GO analysis of these genes implicated several nuclear components such as nucleus, nucleoplasm, and nuclear membrane (Fig. $1 E$ ), suggesting a possible deterioration in nuclear structure or function at aged NMJ. Notably, the expression of two genes encoding nuclear membrane proteins, Lmna (lamin A/C) and Lemd2 (LEM domain containing 2), was reduced (Fig. 1F). Mutations in Lmna have been shown to cause muscular dystrophy and premature aging disease (Bechert et al., 2003; De Sandre-Giovannoli et al., 2003; Eriksson et al., 2003). Lamin A/C mRNA was reduced at $12 \mathrm{M}$ when NMJ degeneration was not apparent (Li et al., 2011), but further reduced at $24 \mathrm{M}$ (Fig. 1G). Similar reduction at the protein level was observed (Fig. 1H,I). Furthermore, lamin A/C 
A

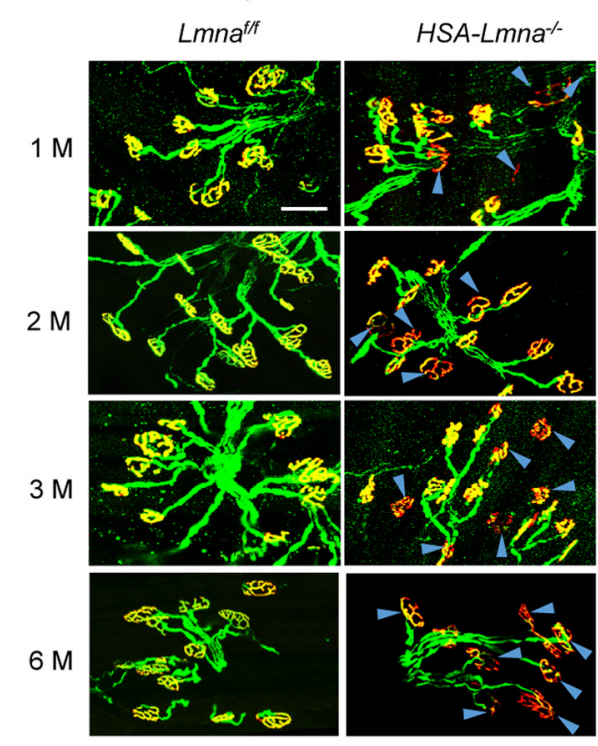

B

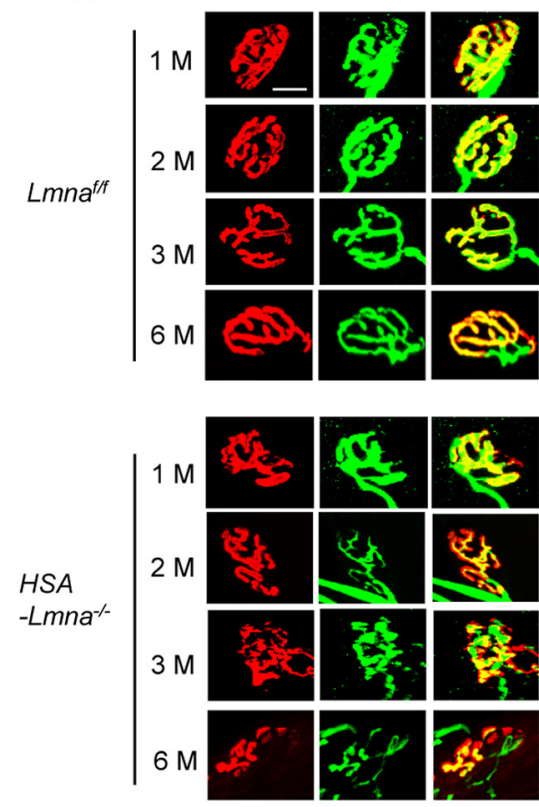

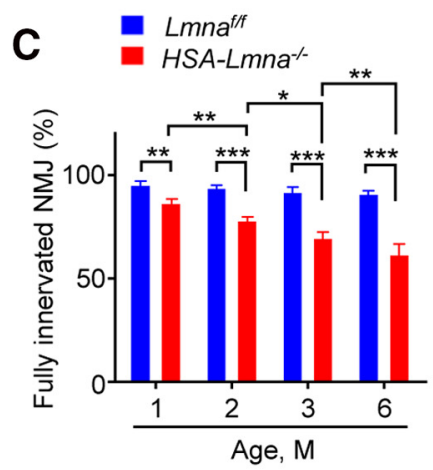

$\mathbf{D}=\begin{aligned} & L m n a^{f / f} \\ & H S A-L m n a^{-/}\end{aligned}$

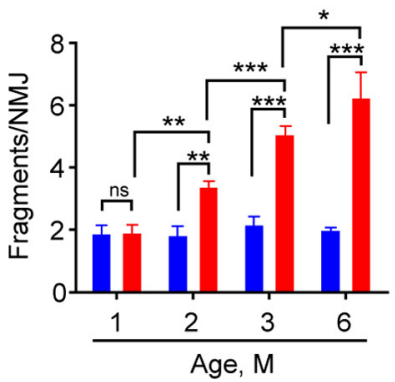

E $\square$ - $L m n a^{f / t}$

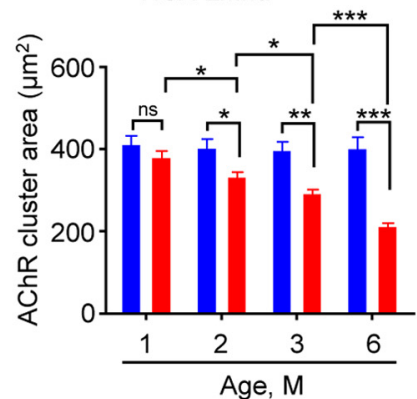

Figure 4. Progressive NMJ degeneration in HSA-Lmna-/- mice. A, B, NMJ morphology deficits in HSA-Lmna-/- mice. TA muscles were stained whole-mount with CF568 $\alpha$-BTX (red) and anti-NF/Syn antibodies (visualized by Alexa Fluor 488, green). $A$, Representative images of TA muscles of control and mutant mice at different ages. Blue arrowheads indicated denervated or partially innervated endplates. Scale bar, $50 \mu \mathrm{m}$. $\boldsymbol{B}$, Enlarged images of the individual NMJs. Scale bar, $20 \mu \mathrm{m}$. C, Progressive decrease in NMJ innervation in mutant mice. Data were shown as mean \pm SEM, $n=5$ mice per group. Control versus mutant: unpaired $t$ test, $t_{(8)}=3.515,{ }^{* *} p=0.0079$ for $1 \mathrm{M} ; t_{(8)}=7.71,{ }^{* * *} p<0.0001$ for $2 \mathrm{M} ; t_{(8)}=6.737$, ${ }^{* * *} p=0.0001$ for $3 \mathrm{M}$; $t_{(8)}=15.39,{ }^{* * *} p<0.0001$ for $6 \mathrm{M}$. Control: one-way ANOVA, $F_{(3,16)}=1.282, p=0.3143$. Mutant: one-way ANOVA, $F_{(3,16)}=41.19 ; 2$ versus $1 \mathrm{M},{ }^{* *} p=0.0078 ; 3$ versus $2 \mathrm{M},{ }^{*} p=0.0289 ; 6$ versus $3 \mathrm{M}^{* *} p=0.0033$. D, Progressive NMJ fragmentation in mutant mice. Data were shown as mean $\pm \mathrm{SEM}, n=5$ mice per group. Control versus mutant: unpaired $t$ test, $t_{(8)}=0.1127$, $p=0.9131$ for $1 \mathrm{M} ; t_{(8)}=4.725,{ }^{* *} p=0.0015$ for $2 \mathrm{M} ; t_{(8)}=8.165$, ${ }^{* * *} p<0.0001$ for $3 \mathrm{M} ; t_{(8)}=10.08,{ }^{* * *} p<0.0001$ for $6 \mathrm{M}$. Control: one-way ANOVA, $F_{(3,16)}=0.4222, p=0.7397$. Mutant: one-way ANOVA, $F_{(3,16)}=47.74 ; 2$ versus $1 \mathrm{M},{ }^{* *} p=0.0012 ; 3$ versus $2 \mathrm{M}$, ${ }^{* * *} p=0.0004 ; 6$ versus $3 \mathrm{M}^{*}{ }^{*} p=0.0159$. E, Progressive reduction in AChR cluster area in mutant mice. Data were shown as mean $\pm \mathrm{SEM}, n=5$ mice per group. Control versus mutant: unpaired $t$ test, $t_{(8)}=1.332, p=0.2196$ for $1 \mathrm{M} ; t_{(8)}=2.986,{ }^{*} p=0.0175$ for $2 \mathrm{M} ; t_{(8)}=4.883$, ${ }^{* *} p=0.0012$ for $3 \mathrm{M} ; t_{(8)}=6.615,{ }^{* * *} p=0.0002$ for $6 \mathrm{M}$. Control: one-way ANOVA, $F_{(3,16)}=0.0835, p=0.9680$. Mutant: one-way ANOVA, $F_{(3,16)}=36.62 ; 2$ versus $1 \mathrm{M}$, ${ }^{*} p=0.04 ; 3$ versus $2 \mathrm{M},{ }^{*} p=0.0286 ; 6$ versus $3 \mathrm{M},{ }^{* * *} p=0.0004$. ns, no significant difference.

protein in SR was reduced at $24 \mathrm{M}$ (Fig. 1J,K). To investigate whether there are molecular changes in subsynaptic nuclei in aged muscles, we isolated muscle SR and analyzed nuclear proteins including LAP2 (LAP2 group of lamin A-associated proteins), HP1 (heterochromatin protein HP1), and heterochromatin-specific trimethylation of Lys9 on histone $\mathrm{H} 3$ (Tri-Me-H3K9), all of which were reduced (Fig. $1 L, M$ ). Concomitantly, the DNA damage marker $\gamma \mathrm{H} 2 \mathrm{AX}$ was increased. These results support the notion that synaptic nuclei may be compromised in aged muscle fibers and may likely involve Lmna deficiency. Indeed, NMJs in Lmna germline knock-out mice were discontinuous or fragmented (Méjat et al., 2009). However, it is not known whether the phenotypes were because of gene loss in muscles or motoneurons and what the underlying mechanisms are.
Progressive NMJ decline in HSA-Lmna-/-, but not HB9-

Lmna-/-, mice

To mutate Lmna in motoneurons, we bred $L m n a^{f / f}$ mice in which exon 2 of the Lmna gene is flanked with loxP sites (Kim and Zheng, 2013) with HB9::Cre mice which express Cre recombinase under the control of the homeobox gene HB9 promoter (Arber et al., 1999; Yang et al., 2001; Wu et al., 2012a; Shen et al., 2018). Resulting compound mice HB9::Cre; Lmna ${ }^{f / f}$ (referred to as HB9-Lmna-/- hereafter) were validated for knock-out of lamin A/C in motoneurons (Fig. 2A,B) and analyzed for NMJ morphology. No difference was observed in NMJs in HB9-Lmna-/- mice as old as $2 \mathrm{M}$ (Fig. 2C,D). Quantitative data reveal similar fully innervated NMJ (Fig. $2 E$ ), NMJ fragmentation (Fig. 2F), and AChR area (Fig. 2G) between the two genotypes, suggesting that lamin $\mathrm{A} / \mathrm{C}$ in 
A

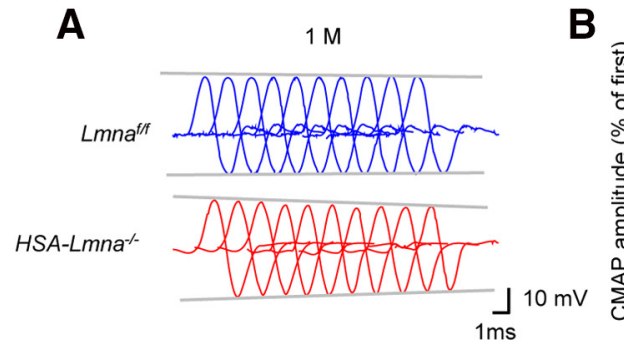

B

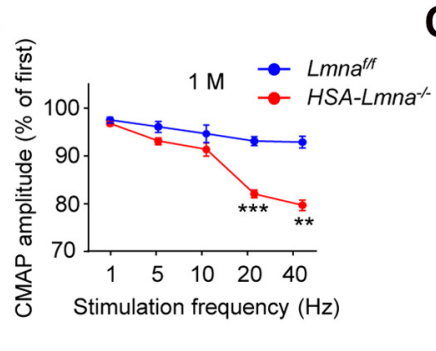

C

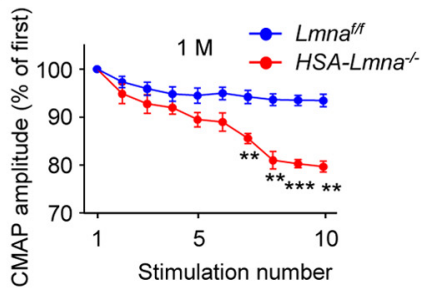

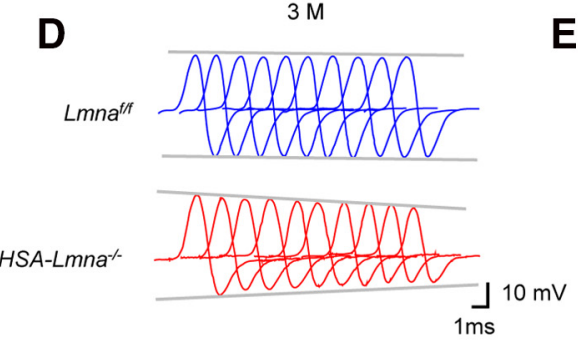

E
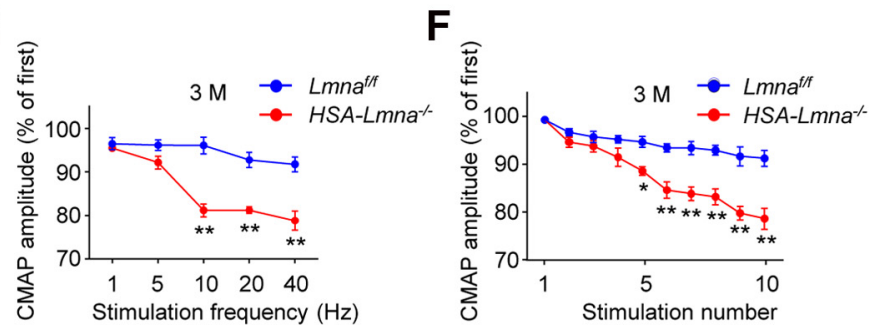

$6 \mathrm{M}$
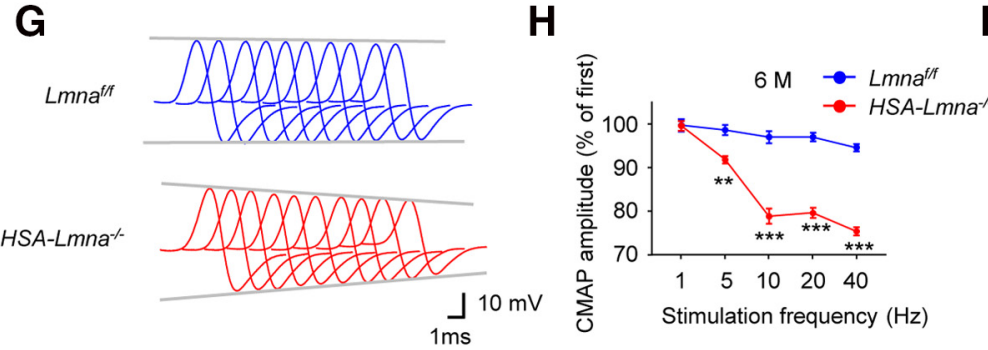

Figure 5. Progressive CMAP deficits in HSA-Lmna-I- mice. $\boldsymbol{A}$, Representative CMAP traces at 40-Hz stimulations for $1 \mathrm{M}$ control and mutant mice. Ten CMAP traces were shown in a stacked succession for comparison. $\boldsymbol{B}$, Frequency-dependent reduction in CMAP amplitude in $1 \mathrm{M}$ mutant mice. Shown were ratios of 10th over the first CMAP amplitudes after stimulation. $F_{\text {(genotype)(1,4) }}=49.97,{ }^{* * *} p=0.0008$ for $20 \mathrm{~Hz},{ }^{* *} p=0.0013$ for $40 \mathrm{~Hz}$. C, Reduced CMAP amplitude at 40-Hz stimulation in $1 \mathrm{M}$ mutant mice. Shown were ratios of the 2nd-10th over the first CMAP amplitudes after stimulation. $F_{\text {(genotype) }(1,4)}=88.31,{ }^{* *} p=0.0080$ for 7 th, ${ }^{* *} p=0.0044$ for 8 th, ${ }^{* * *} p=0.0006$ for 9 th, ${ }^{* *} p=0.0013$ for 10 th. $D$, Representative CMAP traces at 40 $\mathrm{Hz}$ stimulations for $3 \mathrm{M}$ control and mutant mice. $\boldsymbol{E}$, Frequency-dependent reduction in CMAP amplitude in $3 \mathrm{M}$ mutant mice. Shown were ratios of 10th over the first CMAP amplitudes after stimulation. $F_{\text {(genotype)(1,4) }}=280.9,{ }^{* *} p=0.0036$ for $10 \mathrm{~Hz},{ }^{* *} p=0.0034$ for $20 \mathrm{~Hz},{ }^{* *} p=0.0032 \mathrm{for} 40 \mathrm{~Hz}$. F, Reduced CMAP amplitude at $40-\mathrm{Hz}$ stimulation in $3 \mathrm{M}$ mutant mice. Shown were ratios of the 2nd-10th over the first CMAP amplitudes after stimulation. $F_{\text {(genotype) }(1,4)}=258.6,{ }^{*} p=0.0141$ for 5 th, ${ }^{* *} p=0.0098$ for 6 th, ${ }^{* *} p=0.0084$ for 7 th, ${ }^{* *} p=0.0071$ for 8 th, ${ }^{* *} p=0.0075$ for 9 th, ${ }^{* *} p=0.0032$ for 10th. $\boldsymbol{G}$, Representative CMAP traces at $40-\mathrm{Hz}$ stimulations for $6 \mathrm{M}$ control and mutant mice. $\boldsymbol{H}$, Frequency-dependent reduction in CMAP amplitude in 6 $\mathrm{M}$ mutant mice. Shown were ratios of 10 th over the first CMAP amplitudes after stimulation. $F_{\text {(genotype)(1,6) }}=226.2,{ }^{* *} p=0.0033$ for $5 \mathrm{~Hz}$, ${ }^{* * *} p=0.0002$ for $10 \mathrm{~Hz}$, ${ }^{* * *} p<0.0001$ for $20 \mathrm{~Hz}$, ${ }^{* * *} p<0.0001$ for $40 \mathrm{~Hz}$. I, Reduced CMAP amplitude at 40-Hz stimulation in $6 \mathrm{M}$ mutant mice. Shown were ratios of the 2nd-10th over the first CMAP amplitudes after stimulation. $F_{\text {(genotype)(1,6) }}=303.2,{ }^{* *} p=0.0035$ for 4 th, ${ }^{* * *} p=0.0002$ for 5 th, ${ }^{* * *} p<0.0001$ for 6 th, ${ }^{* * *} p<0.0001$ for 7 th, ${ }^{* *} p<0.0001$ for 8 th, ${ }^{* * *} p<0.0001$ for 9 th, ${ }^{* * *} p<0.0001$ for 10 th. Data were shown as mean \pm SEM; two-way ANOVA followed by Bonferroni's post hoc test, $n=4$ mice per group for $6 \mathrm{M}$ and $n=3$ mice per group for rest.

motoneurons may be dispensable for NMJ formation and maintenance within the times of experiments.

To mutate Lmna in skeletal muscles, Lmna f/f mice were bred with HSA::Cre mice, in which Cre recombinase is expressed under the human skeletal $\alpha$-actin (HSA) promotor. The HSA promoter drives gene expression specifically in skeletal muscle as early as embryonic day 9.5 (Muscat and Kedes, 1987; Brennan and Hardeman, 1993) and has been widely used to study NMJ formation (Schwander et al., 2004; Jaworski et al., 2007; Nishimune et al., 2008; Wu et al., 2012a; Li et al., 2016; Zhao et al., 2017). The compound mice, referred to as HSA-Lmna-/-, were viable and showed no sign of muscle weakness in neonatal stages. We examined NMJs in diaphragms and TA muscles using whole-mount staining with $\mathrm{NF} / \mathrm{Syn}$ antibodies to label motoneuron axon terminals (Alexa Fluor 488, green) and CF568- $\alpha$-BTX to label postsynaptic AChR ( $\alpha$-BTX, red). At postnatal day (P)0, the NMJs between HSALmna-/ - mice and control Lmna f/f mice were similar, with no difference in the width of endplate bands (Fig. 3C), number of secondary nerve branches (Fig. 3D), length of secondary branches (Fig. $3 E$ ), or areas of AChR clusters (Fig. 3F). These results suggest that muscle lamin $\mathrm{A} / \mathrm{C}$ is not necessary for NMJ formation in mice.
Interestingly, NMJs displayed a progressive decline in $H S A$ Lmna-/- mice (Fig. 4). In $1 \mathrm{M}$ control mice, $95.2 \%$ of NMJs were fully innervated; it was reduced to $86.7 \%$ in age-matched mutant mice (Fig. 4A,C). There was little change in fully innervated NMJs in controls from 1 to $3 \mathrm{M}$ (Fig. 4C, blue); however, in mutant mice, fully innervated NMJ further decreased to $78.1 \%$ at $2 \mathrm{M}$ and to $69.8 \%$ at $3 \mathrm{M}$ (Fig. $4 \mathrm{C}$, red). NMJ fragmentation was similar between $1 \mathrm{M}$ control and mutant mice, but was increased in mutant mice at 2 and $3 \mathrm{M}$ compared with age-matched control mice (Fig. 4B,D). Notably, fragmentation numbers per NMJ in mutant mice increased from $3.40 \pm 0.18$ at $2 \mathrm{M}$ and to $5.10 \pm 0.24$ at $3 \mathrm{M}$ while there is no difference in control mice 1 through $3 \mathrm{M}$. Similarly, progressive reduction of AChR cluster area was also observed in mutant mice (403 and $334 \mu \mathrm{m}^{2}$ at $2 \mathrm{M}$ for control and mutant mice, respectively; 398 and $292 \mu \mathrm{m}^{2}$ at $3 \mathrm{M}$ for control and mutant, respectively; Fig. $4 B, E$ ). At $6 \mathrm{M}$, mutant mice showed more severe deficits in NMJ morphology (denervation, fragmentation, and AChR cluster area). These findings indicated a progressive NMJ degeneration in the absence of lamin $\mathrm{A} / \mathrm{C}$ in muscles. 


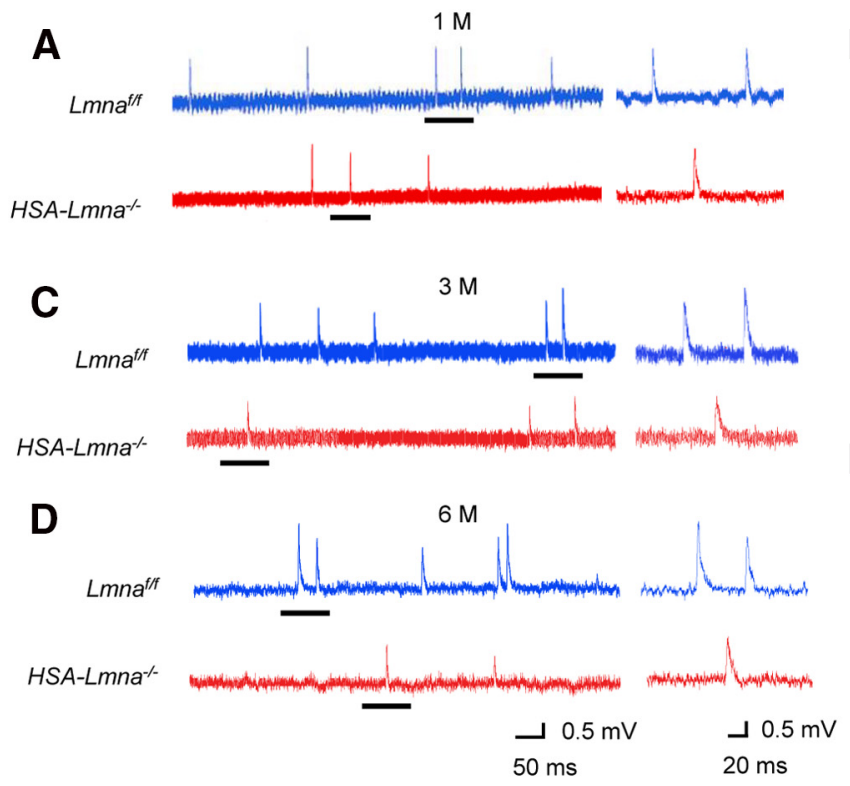

B

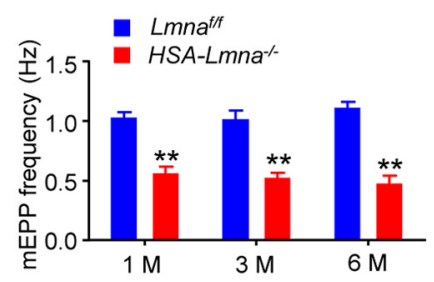

E

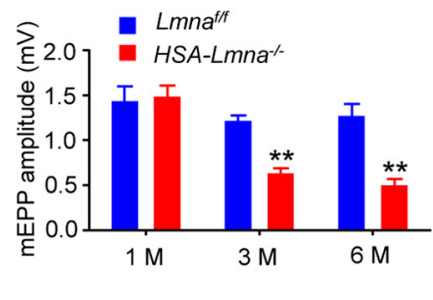

Figure 6. Progressive NMJ transmission deficits in HSA-Lmna-I- mice. Progressive reduction in mEPP frequency and amplitude in mutant mice. $A, C, D$, Representative mEPP traces of 1 $M(A), 3 \mathrm{M}(\boldsymbol{C})$, and $6 \mathrm{M}(\boldsymbol{D})$ control and mutant mice. Underlined regions on the left were enlarged and shown on the right. $\boldsymbol{B}$, Reduced mEPP frequency in mutant mice at different ages; $t_{(4)}$ $=7.730,{ }^{* *} p=0.0015$ for $1 \mathrm{M} ; t_{(4)}=6.361,{ }^{* *} p=0.0031$ for $3 \mathrm{M} ; t_{(4)}=8.497,{ }^{* *} p=0.0011$ for $6 \mathrm{M}$. $E$, Reduced mEPP amplitude in mutant mice at 3 and 6 but not $1 \mathrm{M} ; t_{(4)}=0.2594$, $p=0.8081$ for $1 \mathrm{M} ; t_{(4)}=8.151,{ }^{* *} p=0.0012$ for $3 \mathrm{M} ; t_{(4)}=5.823,{ }^{* *} p=0.0043$ for $6 \mathrm{M}$. Data were shown as mean \pm SEM, unpaired $t$ test, $n=3$ mice per group.

Progressive impairment in NMJ transmission in $H S A$ -

Lmna-/- mice

To evaluate the functional consequences of aberrant NMJ maintenance in HSA-Lmna-/- mice, we probed neuromuscular transmission by measuring CMAP and mEPPs. For CMAP assay, action potentials were triggered by 10 consecutive nerve stimuli (Grob and Harvey, 1953; Elmqvist et al., 1977; Barik et al., 2014; Patten et al., 2017; Zhao et al., 2017). As shown in Figure 5B, CMAP amplitudes at the 10th stimuli at 1, 5, and $10 \mathrm{~Hz}$ were similar in control and mutant mice at the age of $1 \mathrm{M}$. However, the amplitudes were reduced at 20 and $40 \mathrm{~Hz}$ of stimulation frequency (Fig. 5B). Amplitude reduction was observed beginning at $10 \mathrm{~Hz}$ in $3 \mathrm{M}$ mutant mice and $5 \mathrm{~Hz}$ in $6 \mathrm{M}$ mutant mice (Fig. 5E,H). Next, we stimulated CMAP amplitudes at 10 consecutive stimuli at $40 \mathrm{~Hz}$ (Fig. $4 A, D, G$ ). At $1 \mathrm{M}$, mutant mice did not show a reduction until the 7th stimulus (Fig. 5C); however, the reduction was observed at the 5 th stimulus for $3 \mathrm{M} \mathrm{mu}$ tant mice (Fig. $5 F$ ) and 4 th stimulus for $6 \mathrm{M}$ mutant mice (Fig. $5 I$ ). These data pointed to a progressive impairment in NMJ transmission in mutant mice.

To investigate underlying cellular mechanisms of neuromuscular transmission deficits, we measured mEPPs, local depolarizations in response to spontaneous ACh release (Fatt and Katz, 1952; Shen et al., 2018; Zhao et al., 2018; Xing et al., 2019). mEPP frequency decreased in 1,3 , and $6 \mathrm{M}$ mutant mice compared with control (Fig. 6A-D), suggesting impairment in ACh release. mEPP amplitude was similar between $1 \mathrm{M}$ control and mutant mice but was decreased in 3 and $6 \mathrm{M}$ mutants, suggesting a progressive reduction in postsynaptic AChR density at the NMJ (Fig. $6 A, C-E)$. These results indicate reduced CMAPs in response to higher frequency stimulation and miniature EPSC (mEPSC) frequency in $1 \mathrm{M}$ mutant mice and the reduction appeared to be progressive. Together with morphologic studies (Fig. 4C-E), these observations indicate that functional deficits occurred as early as 1 $\mathrm{M}$ in mutant mice when deficits in NMJ morphology were not apparent, suggesting that neurotransmissions are a more sensitive
A Laminin/DAP
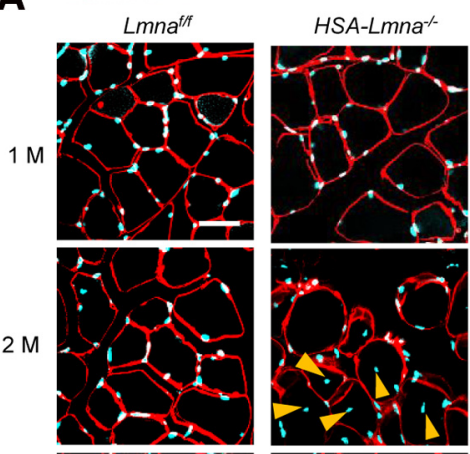

B
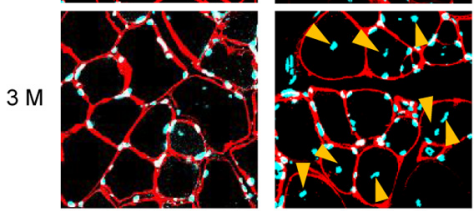

C

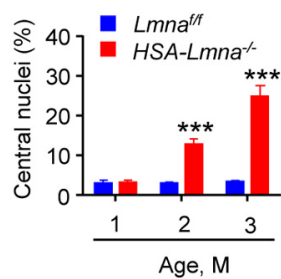

Figure 7. Reduced muscle size and increased central nuclei in HSA-Lmna-/- mice. A, Cross-sections of TA muscles were stained with laminin antibody (visualized by Alexa Fluor 594 , red) and DAPI (blue). Yellow arrowheads, central nuclei. Scale bar, $20 \mu \mathrm{m}$. B, Reduced cross-section area in $3 \mathrm{M}$ mutant mice compared with control mice. Data were shown as mean $\pm \mathrm{SEM}, t_{(8)}=0.2521, p=0.8073$ for $1 \mathrm{M} ; t_{(8)}=0.0353, p=0.9729$ for $2 \mathrm{M} ; t_{(8)}=$ $2.391,{ }^{*} p=0.0438$ for $3 \mathrm{M}$; unpaired $t$ test, $n=5$ mice per group. $C$, Increased central nuclei in 2 and $3 \mathrm{M}$ mutant mice compared with control mice. Data were shown as mean $\pm \mathrm{SEM}$, $t_{(8)}=0.110, p=0.9154$ for $1 \mathrm{M} ; t_{(8)}=6.968,{ }^{* * *} p=0.0001$ for $2 \mathrm{M} ; t_{(8)}=7.614$, ${ }^{* * *} p<0.0001$ for $3 \mathrm{M}$; unpaired $t$ test, $n=5$ mice per group.

indicator of NMJ decline. In addition, both morphologic and functional deficits are progressive with time.

Lmna mutation has been shown to impair muscle development (Sullivan et al., 1999; Frock et al., 2006; Cohen et al., 2013). In parallel experiments, we analyzed the morphology of muscle fibers and quantified their diameters and central nuclei, an indicator of muscle regeneration. As shown in Figure 7, the size of muscle fibers was similar between control and mutant mice at 
A

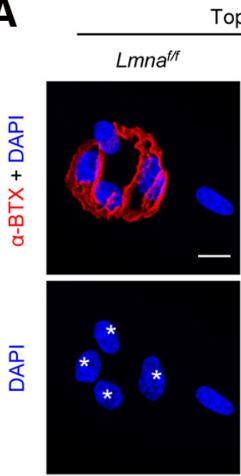

Top view HSA-Lmna $\%$
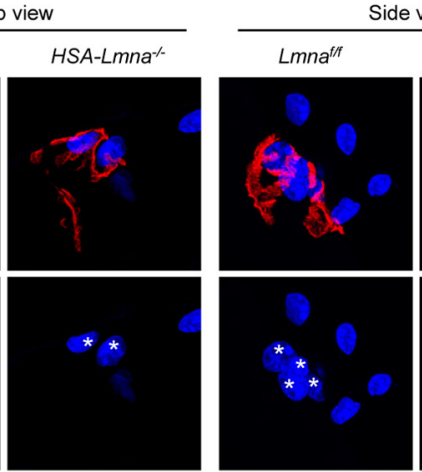
HSA-Lmna $\%$

B

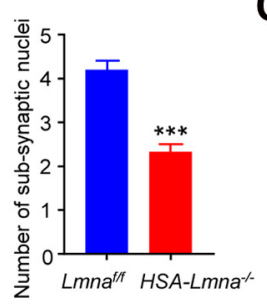

C

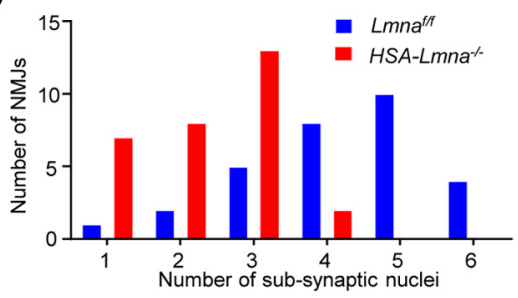

D
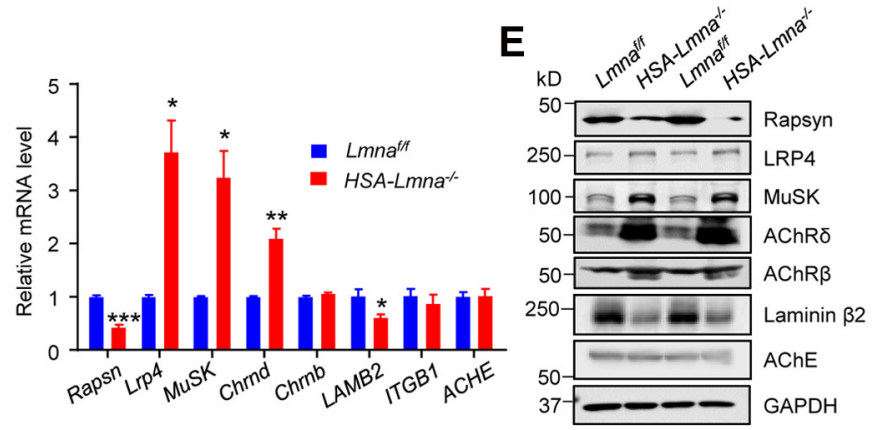

$\mathbf{F}$

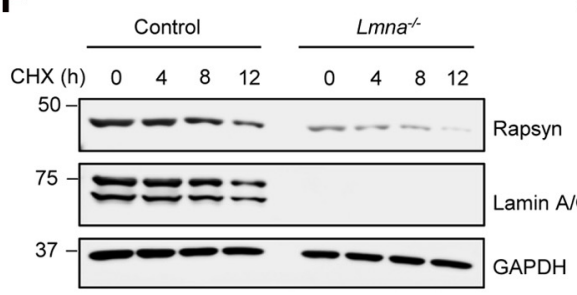

G

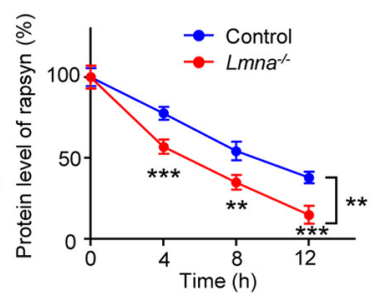

Figure 8. Reduced rapsyn levels in HSA-Lmna-/- mice. $A$, Representative images of single muscle fiber in $3 \mathrm{M}$ control and mutant mice. Muscle fibers were stained with (F568-conjugated $\alpha$-BTX (red) and DAPI (blue). Scale bar, $10 \mu \mathrm{m}$. White asterisk, subsynaptic nucleus. $\boldsymbol{B}$, Quantification of data in $\boldsymbol{A}$ showed decreased subsynaptic nuclei in mutant muscle. Data were shown as mean \pm SEM $, t_{(58)}=6.513,{ }^{* * *} p<0.0001$; unpaired $t$ test, $n=30$ NMJs from 3 mice per group. $C$, Histograms showed the distribution of data in $\boldsymbol{B}$. $\boldsymbol{D}$, Reduced rapsyn mRNA levels in mutant mice. Data were shown as mean $\pm S E M, t_{(4)}=10.36$, ${ }^{* * *} p=0.0005$ for Rapsyn; $t_{(4)}=4.505,{ }^{*} p=0.0108$ for Lrp4; $t_{(4)}=4.480,{ }^{*} p=0.0110$ for MuSK; $t_{(4)}=5.919,{ }^{* *} p=0.0041$ for Chrnd; $t_{(4)}=1.960, p=0.1216$ for Chrnb; $t_{(4)}=2.777,{ }^{*} p=0.05$ for LAMB2; $t_{(4)}=0.6521, p=0.5499$ for ITGB1; $t_{(4)}=0.099$, $p=0.9255$ for ACHE. Unpaired $t$ test, $n=3$ mice per group. $\boldsymbol{E}$, Reduced rapsyn protein level from mutant muscles. $\boldsymbol{F}$, Reduced rapsyn stability in Lmna mutant myotubes. C2C12 myotubes were treated with cycloheximide (CHX, $50 \mu \mathrm{g} / \mathrm{ml})$ for indicated times and blotted for rapsyn. Protein level at $0 \mathrm{~h}$ in each individual group was normalized to $100 \%$, respectively. $\mathbf{G}$, Quantitative analysis for data in $\boldsymbol{F}$. $F_{\text {(genotype)(1,4) }}=23.35,{ }^{* *} p=0.0084 ;{ }^{* * *} p=0.0007$ for $4 \mathrm{~h},{ }^{* *} p=0.0013$ for $8 \mathrm{~h},{ }^{* * *} p=0.0002$ for $12 \mathrm{~h}$. Data were shown as mean \pm SEM; two-way ANOVA followed by Bonferroni's post hoc test, $n=3$ independent experiments.

ages of 1 and $2 \mathrm{M}$, but slightly reduced in $3 \mathrm{M} \mathrm{HSA-Lmna-/-}$ mice (Fig. 7A,B). Central nuclei were similar between the two genotypes in $1 \mathrm{M}$ mice but increased in mutant mice at the ages of 2 and $3 \mathrm{M}$ (Fig. 7A,C). As described above, muscle fiber deficits in HSA-Lmna-/- mice appeared to be lagging behind the NMJ deficits, in particular functional deficits which were apparent as early as $1 \mathrm{M}$ of age. These observations suggest that the NMJ may be a primary target of Lmna mutation, i.e., NMJ deficits may not be secondary to muscle impairment.

\section{Alleviated NMJ deficits in HSA-Lmna-/ - mice by rapsyn expression}

To explore underlying molecular mechanisms by which Lmna mutation leads to NMJ degeneration, we first stained the single muscle fiber isolated from control and mutant mice. We found while control NMJs had approximately four nuclei underneath the postsynaptic membrane, mutant NMJs contained fewer (approximately two) subsynaptic nuclei (Fig. 8A-C). These results may suggest dislocation of synaptic nuclei in mutant muscle. Next, we examined the mRNA and protein levels for a handful of molecules involved in NMJ formation and maintenance. Quantitative real-time PCR showed lower mRNA levels of Rapsn in mutant muscles compared with control. Lrp4, MuSK, and Chrnd were increased, and Chrnb remained unaffected (Fig. 8D). Similar changes in these molecules were observed at protein levels (Fig. $8 E$ ). Moreover, laminin $\beta 2 \mathrm{mRNA}$ and protein were reduced in mutant muscles (Fig. $8 D, E$ ), revealing a potential mechanism for presynaptic deficits. However, the turnover rate of rapsyn was increased in lamin $\mathrm{A} / \mathrm{C}$ knock-out $\mathrm{C} 2 \mathrm{C} 12$ myotubes in the presence of cycloheximide (CHX; Fig. $8 F, G$ ). Collectively, our data suggest lamin $\mathrm{A} / \mathrm{C}$ may be necessary for NMJ maintenance by regulating transcription and posttranscriptional mechanisms.

Considering the critical role of rapsyn in NMJ formation and maintenance, we examined if increasing rapsyn levels in muscles ameliorate NMJ deficits in HSALmna-I- mice. HSA-Lmna-/- mice were crossed with HSA-Rapsyn transgenic mice (referred to as Rapsyn-Tg) that express rapsyn under the control of HSA promoter (Li et al., 2016). Increased expression of rapsyn was validated by Western blotting (Fig. $9 A-C)$. NMJs were examined at the age of 3 $M$. There were more fully innervated NMJs in $3 \mathrm{M}$ HSA-Lmna-/-; Rapsyn-Tg mice, compared with HSA-Lmna-/- mice (Fig. $9 D, E)$. NMJ fragment numbers were reduced by rapsyn expression (Fig. 9D,F). Additionally, AChR cluster area was increased from $305 \pm 13.0$ in HSA-Lmna-/mice to $354 \pm 7.66 \mu \mathrm{m}^{2}$ in HSA-Lmna-/-; Rapsyn-Tg mice (Fig. 9G). Rapsyn expression also improved NMJ transmission. The 10th to 1st ratios of CMAP at 20 and $40 \mathrm{~Hz}$ of stimulation was $82.3 \%$ and $79.7 \%$ in HSA-Lmna-/- mice, and were increased to $88.4 \%$ and 87.3\% in HSA-Lmna-/-; Rapsyn-Tg mice (Fig. 9I). At $40 \mathrm{~Hz}$, CMAP reduction observed in HSA-Lmna-/ - was also diminished in HSA-Lmna-/-; Rapsyn-Tg (Fig. 9H,J). Reduction in 


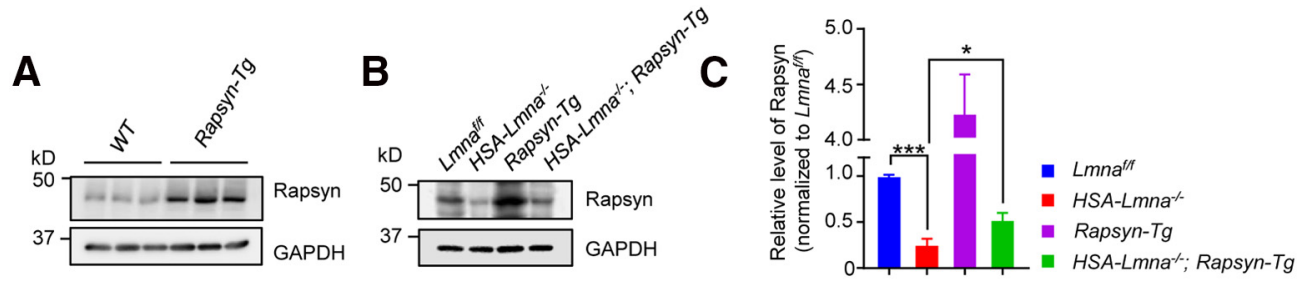

D

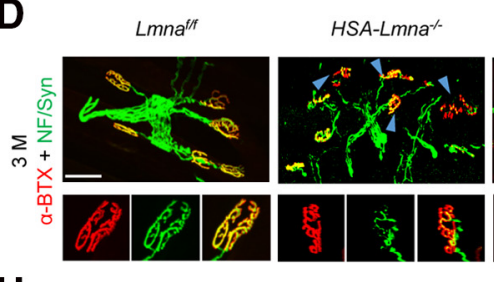

H

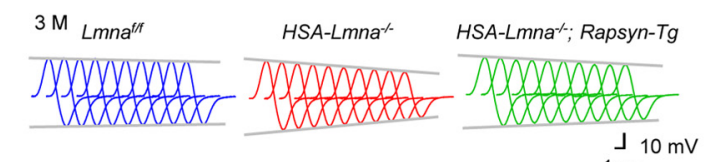

K

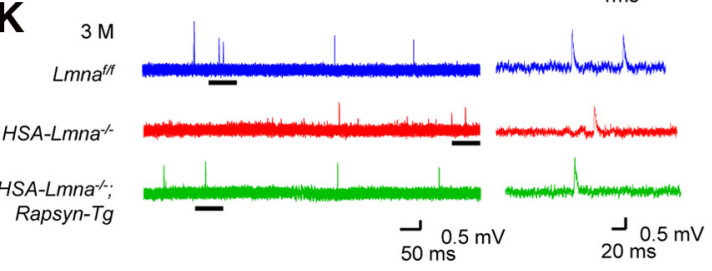

HSA-Lmna ${ }^{-\alpha}$

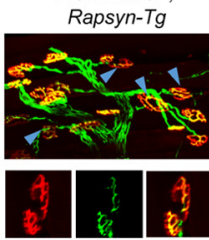

E

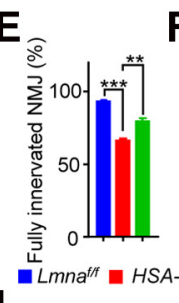

$F$

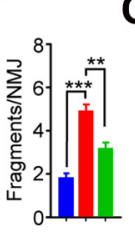

$\mathbf{G}_{\widetilde{\pi}}$

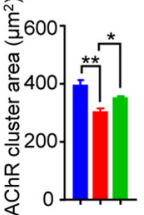

HSA-Lmna $\%$ Rapsyn-Tg

I.

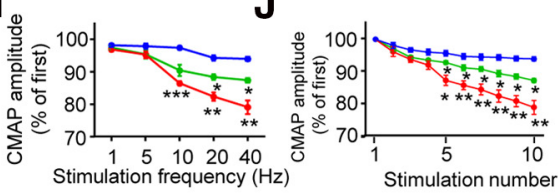

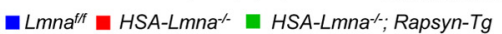

L

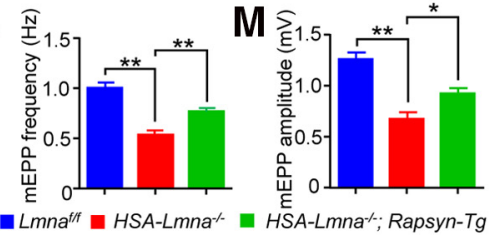

Figure 9. Alleviated NMJ deficits in HSA-Lmna-/ - mice by rapsyn expression. A, Overexpression of rapsyn in TA muscles of $2 \mathrm{M}$ Rapsyn-Tg mice. $\boldsymbol{B}$, Elevated rapsyn protein in HSALmna- I-; Rapsyn-Tg muscles. C, Quantitative analysis for data in B. Data were shown as mean \pm SEM. Lmnaf ${ }^{f / f}$ versus HSA-Lmna- $-, t_{(4)}=11.44,{ }^{* * *} p=0.0003 ;$ HSA-Lmna $-/-$ versus HSA-Lmna $-/-;$ Rapsyn- $T g, t_{(4)}=2.822,{ }^{*} p=0.0477$. Unpaired $t$ test, $n=3$ mice per group. D, Improved NMJ morphologic deficits in HSA-Lmna $-/-$ mice by rapsyn expression. Top, TA muscles of mice from different ages and indicated genotypes were whole-mount stained with (F568 $\alpha$-BTX (red) and anti-NF/Syn antibodies (green). Blue arrowhead, denervated or partially innervated NMJ. Scale bar, $50 \mu \mathrm{m}$. Bottom, Enlarged images of individual NMJ. Scale bar, $20 \mu \mathrm{m}$. E-G, Quantitative analysis of data in $\boldsymbol{D}$. E, Rescue of NMJ denervation in HSA-Lmna-I-

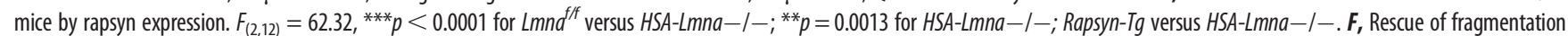
in HSA-Lmna $-1-$ mice by rapsyn expression. $F_{(2,12)}=31.41,{ }^{* * *} p<0.0001$ for $\operatorname{Lmn} a^{f / f}$ versus HSA-Lmna-I-; ${ }^{* *} p=0.0040$ for HSA-Lmna-I-; Rapsyn-Tg versus HSA-Lmna-I-. G, Rescue of reduced AChR cluster area in HSA-Lmna $-/$ - mice by rapsyn expression. $F_{(2,12)}=10.39,{ }^{* *} p=0.0045$ for Lmna ${ }^{f / f}$ versus HSA-Lmna $-/-;{ }^{*} p=0.0115$ for HSA-Lmna $-I-;$ RapsynTg versus HSA-Lmna-I- Data were shown as mean \pm SEM, one-way ANOVA with Tukey's multiple comparison test, $n=5$ mice per genotype. H-J, Increased CMAP amplitudes of HSALmna-I- mice by rapsyn expression. $\boldsymbol{H}$, Representative CMAP traces at 40-Hz stimulations. $\boldsymbol{I}$, Rescue of frequency-dependent CMAP reduction in HSA-Lmna-I-; Rapsyn-Tg mice. Shown were ratios of the 10th over the first CMAP amplitudes. For $5 \mathrm{~Hz}$, Lmna ${ }^{f / f}$ versus HSA-Lmna-/-, $p=0.1081$; HSA-Lmna-/-; Rapsyn-Tg versus HSA-Lmna- /,$p=0.9472$. For $10 \mathrm{~Hz}$, Lmna $a^{f / f}$ ver-

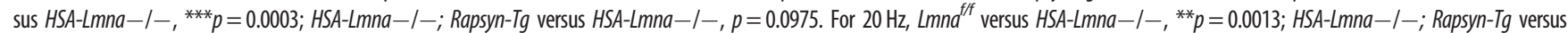
HSA-Lmna-,$-{ }^{*} p=0.0164$. For $40 \mathrm{~Hz}$, Lmna ${ }^{f / f}$ versus HSA-Lmna-,$-{ }^{* *} p=0.0026 ;$ HSA-Lmna $-1-;$ Rapsyn-Ig versus HSA-Lmna $-1-,{ }^{*} p=0.0204$. Data were shown as mean \pm SEM, $F_{\text {(genotype)(2,6) }}=49.23$, two-way ANOVA followed by Bonferroni's post hoc test, $n=3$ mice per genotype. J, Reduced ratio of 2nd-10th CMAP amplitudes over the first CMAP amplitude at 40-Hz stim-

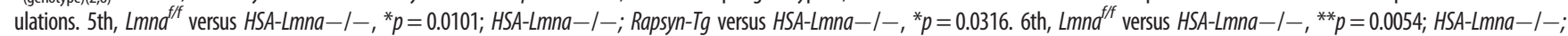
Rapsyn-Tg versus HSA-Lmna-,$-{ }^{*} p=0.0307 .7$ th, Lmna ${ }^{f / f}$ versus HSA-Lmna- $/-,{ }^{* *} p=0.0067 ;$ HSA-Lmna $-/-;$ Rapsyn-Tg versus HSA-Lmna- $/-,{ }^{*} p=0.0268 .8$ th, Lmna ${ }^{f / f}$ versus HSA-

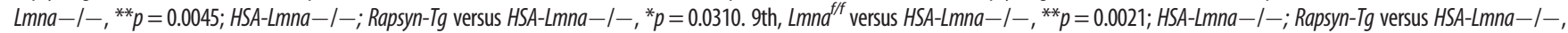
${ }^{*} p=0.0166$. 10th, $L m n a^{f / f}$ versus HSA-Lmna $-/-,{ }^{* *} p=0.0026 ;$ HSA-Lmna $-/-;$ Rapsyn-Tg versus HSA-Lmna-,$-{ }^{*} p=0.0204$. Data shown as mean \pm SEM, $F_{\text {(genotype)(2,6) }}=16.97$, two-way ANOVA followed by Bonferroni's post hoc test, $n=3$ mice per genotype. $\boldsymbol{K}-\boldsymbol{M}$, Increased mEPP frequencies and amplitudes in HSA-Lmna-I- mice by rapsyn expression. $\boldsymbol{K}$, Representative mEPP traces. $L$, Increased mEPP frequencies in HSA-Lmna-/-; Rapsyn-Tg mice compared with HSA-Lmna-/ - mice. Data were shown as mean \pm SEM, $F_{(2,6)}=29.40,{ }^{* *} p=0.0022$ for $L m n a^{f / f}$ versus HSA-Lmna-1-; ;* $=0.0078$ for HSA-Lmna-/-; Rapsyn-Tg versus HSA-Lmna-/-; one-way ANOVA with Tukey's multiple comparison test, $n=3$ mice per genotype. M, Increased mEPP amplitudes in HSA-Lmna-I-; Rapsyn-Tg mice compared with HSA-Lmna-/ - mice. Data were shown as mean $\pm S E M, F_{(2,6)}=30.27$, ${ }^{* *} p=0.0017$ for Lmna $^{f / f}$ versus HSA-Lmna-/-; ${ }^{*} p=0.0208$ for HSA-Lmna-I-; Rapsyn-Tg versus HSA-Lmna-I-; one-way ANOVA with Tukey's multiple comparison test, $n=3$ mice per genotype.

mEPP frequency and amplitude were also attenuated in HSALmna-I-; Rapsyn-Tg mice compared with HSA-Lmna-Imice of the same age (Fig. $9 K-M$ ). These observations demonstrated that compromised NMJ transmission in HSA-Lmna-/was mitigated by restoring rapsyn levels in muscles.

\section{Discussion}

Here, we provide evidence for a role of lamin A/C deficiency in $\mathrm{NMJ}$ aging. We showed that deletion of lamin A/C from skeletal muscle impaired NMJ morphologically and functionally, whereas lack of lamin A/C in motoneurons had little effect. The NMJ deficits appear before the reduction of muscle diameters and the increase of central nuclei, suggesting the NMJ may be a primary target of Lmna mutation. Interestingly, rapsyn was reduced in Lmna mutant muscles, and overexpressing rapsyn mitigated NMJ deficits in HSA-Lmna-/- mutant mice.

During aging, NMJ decline may contribute to skeletal muscle weakness. There is evidence that NMJ fragmentation occurs along with aging; AChR clusters become discontinuous and distributed in dispersed areas in aged mice, compared with pretzellike clusters in young adults (Valdez et al., 2010; Zhao et al., 
2018). Moreover, AChR clusters show a reduced density of $\alpha$-BTX staining in aged muscles (Zhao et al., 2018). Presynaptically, there is a gradual loss of motoneurons in aged human subjects (Berger and Doherty, 2010; Rowan et al., 2012). In mice, results were controversial about motoneuronal loss (Valdez et al., 2010; Chai et al., 2011). Nevertheless, motoneuron axons in aged mice display varicosities, denervation, and multiinnervation (Li et al., 2018). Functionally, a recent study revealed a decline of neuromuscular transmission in $24 \mathrm{M}$ mice compared with $3 \mathrm{M}$ group (Zhao et al., 2018) although no neuromuscular transmission deficits were observed between 26 and $12 \mathrm{M}$ mice (Willadt et al., 2016). However, mechanisms underlying NMJ decline in aging are far from fully understood.

Here, we identified genes that were decreased in aged muscles through RNA-seq. GO analysis of genes whose expression was reduced reveal nuclear-related structures such as nucleus, nucleoplasm, perinuclear region, and nuclear membrane (Fig. $1 E$, $F)$. In accord, we found structural and functional defects in subsynaptic nuclei (Fig. $1 L$ ), which are believed to mediate synapsespecific transcription for $\mathrm{NMJ}$ formation and maintenance (Wu et al., 2010; Li et al., 2018). In particular, two nuclear membrane proteins, Lmna (lamin A/C) and Lemd2 (LEM domain containing 2), were reduced (Fig. 1F). We specifically studied Lmna because of its association with aging-related disorders such as Hutchinson-Gilford progeria syndrome and muscular dystrophy (Novelli and D'Apice, 2003). Lamin A/C, the protein encoded by Lmna gene, is an intermediate filament protein. Its null mutation led to NMJ degeneration (Méjat et al., 2009).

By cell-specific ablation of Lmna, we demonstrate that muscle, but not motoneuron, lamin $\mathrm{A} / \mathrm{C}$, is critical to $\mathrm{NMJ}$ maintenance. How lamin $\mathrm{A} / \mathrm{C}$ regulates the $\mathrm{NMJ}$ maintenance remains unclear. Intriguingly, the mutant mice had fewer nuclei in the NMJ region, suggesting perhaps that it is necessary for aggregating synaptic nuclei (Fig. 8A-C). Moreover, compromised nuclear envelope may alter the expression of genes critical to NMJ maintenance (Burke and Stewart, 2002; Bechert et al., 2003; Bakay et al., 2006). AChR $\delta$ and $\beta$ subunit increased in Lmna mutant muscles (Fig. $8 E$ ), suggesting that NMJ decline may not because of a reduction in AChR proteins. Recent work indicates that the agrin-LRP4-MuSK signaling is not only important for NMJ formation but also critical for its maintenance (Hesser et al., 2006; Samuel et al., 2012; Barik et al., 2014). In Lmna mutant muscles, we found higher mRNA and protein levels of LRP4 and MuSK (Fig. 8D,E), suggesting that agrin-LRP4-MuSK signaling may not be compromised. However, both the mRNA and protein levels of rapsyn reduced (Fig. $8 D, E$ ). Rapsyn is thought to bridge the AChR with the cytoskeleton and serves an E3 ligase whose enzymatic activity is necessary for NMJ formation (Apel et al., 1997; Wu et al., 2010; Li et al., 2016, 2018). In particular, rapsyn appeared to be less stable in lamin $\mathrm{A} / \mathrm{C}$ mutant $\mathrm{C} 2 \mathrm{C} 12$ myotubes (Fig. 8F,G), suggesting lamin A/C may regulate rapsyn turnover. Noticeably, HSA-Lmna-/- mice displayed a reduction in mEPP frequency, suggesting presynaptic deficits. One possible explanation is the loss of laminin $\beta 2$ (Fig. $8 D, E$ ), which is important for aligning and maintaining active zones on presynaptic membranes by interacting with $\mathrm{P} / \mathrm{Q}$-type calcium channels (Nishimune et al., 2004). In mice lacking laminin $\beta 2$, active zones form but cannot be maintained (Noakes et al., 1995), and mEPP frequency is reduced (Knight et al., 2003). Together, these observations support a model that Lmna contributes to NMJ maintenance by stabilizing rapsyn.

Interestingly, transgenic expression of rapsyn was able to diminish NMJ deficits in Lmna mutant mice, AChR clusters were increased and less fragmented, $\mathrm{NMJ}$ innervation was increased, and neuromuscular transmission was improved in HSA-Lmna-/-; Rapsyn-Tg mice, compared with HSA-Lmna-/- mice. These results suggest that rapsyn may be a downstream target of lamin A/ C. On the other hand, replenished rapsyn may improve the cytoskeleton network and/or increase E3 ligase activity in the postsynaptic region and consequently benefit the postsynaptic nuclei and their gene expression. Better postsynaptic structure and function are known to improve presynaptic functions at the NMJ (Pérez-García and Burden, 2012; Miyoshi et al., 2017; Zhao et al., 2018; Eguchi et al., 2020). Future work is needed to investigate underlying mechanisms.

\section{References}

Apel ED, Roberds SL, Campbell KP, Merlie JP (1995) Rapsyn may function as a link between the acetylcholine receptor and the agrin-binding dystrophin-associated glycoprotein complex. Neuron 15:115-126.

Apel ED, Glass DJ, Moscoso LM, Yancopoulos GD, Sanes JR (1997) Rapsyn is required for MuSK signaling and recruits synaptic components to a MuSK-containing scaffold. Neuron 18:623-635.

Arber S, Han B, Mendelsohn M, Smith M, Jessell TM, Sockanathan S (1999) Requirement for the homeobox gene $\mathrm{Hb} 9$ in the consolidation of motor neuron identity. Neuron 23:659-674.

Bakay M, Wang Z, Melcon G, Schiltz L, Xuan J, Zhao P, Sartorelli V, Seo J, Pegoraro E, Angelini C, Shneiderman B, Escolar D, Chen YW, Winokur ST, Pachman LM, Fan C, Mandler R, Nevo Y, Gordon E, Zhu Y, et al. (2006) Nuclear envelope dystrophies show a transcriptional fingerprint suggesting disruption of Rb-MyoD pathways in muscle regeneration. Brain 129:996-1013.

Balice-Gordon RJ (1997) Age-related changes in neuromuscular innervation. Muscle Nerve 20:83-87.

Barik A, Lu Y, Sathyamurthy A, Bowman A, Shen C, Li L, Xiong W-c, Mei L (2014) LRP4 is critical for neuromuscular junction maintenance. J Neurosci 34:13892-13905.

Bechert K, Lagos-Quintana M, Harborth J, Weber K, Osborn M (2003) Effects of expressing lamin A mutant protein causing Emery-Dreifuss muscular dystrophy and familial partial lipodystrophy in HeLa cells. Exp Cell Res 286:75-86.

Berger MJ, Doherty TJ (2010) Sarcopenia: prevalence, mechanisms, and functional consequences. Interdiscip Top Gerontol 37:94-114.

Brennan KJ, Hardeman EC (1993) Quantitative analysis of the human $\alpha$-skeletal actin gene in transgenic mice. J Biol Chem 268:719-725.

Broers JLV, Ramaekers FCS, Bonne G, Yaou RB, Hutchison CJ (2006) Nuclear lamins: laminopathies and their role in premature ageing. Physiol Rev 86:967-1008.

Burden SJ, Depalma RL, Gottesman GS (1983) Crosslinking of proteins in acetylcholine receptor-rich membranes: association between the $\beta$-subunit and the $43 \mathrm{kd}$ subsynaptic protein. Cell 35:687-692.

Burke B, Stewart CL (2002) Life at the edge: the nuclear envelope and human disease. Nat Rev Mol Cell Biol 3:575-585.

Burke B, Stewart CL (2006) The laminopathies: the functional architecture of the nucleus and its contribution to disease. Annu Rev Genomics Hum Genet 7:369-405.

Burke B, Stewart CL (2013) The nuclear lamins: flexibility in function. Nat Rev Mol Cell Biol 14:13-24.

Chai RJ, Vukovic J, Dunlop S, Grounds MD, Shavlakadze T (2011) Striking denervation of neuromuscular junctions without lumbar motoneuron loss in geriatric mouse muscle. PLoS One 6:e28090.

Chevessier F, Girard E, Molgó J, Bartling S, Koenig J, Hantaï D, Witzemann $\mathrm{V}$ (2008) A mouse model for congenital myasthenic syndrome due to MuSK mutations reveals defects in structure and function of neuromuscular junctions. Hum Mol Genet 17:3577-3595.

Cohen TV, Gnocchi VF, Cohen JE, Phadke A, Liu H, Ellis JA, Foisner R, Stewart CL, Zammit PS, Partridge TA (2013) Defective skeletal muscle growth in lamin $\mathrm{A} / \mathrm{C}$-deficient mice is rescued by loss of Lap $2 \alpha$. Hum Mol Genet 22:2852-2869.

De Sandre-Giovannoli A, Chaouch M, Kozlov S, Vallat JM, Tazir M, Kassouri N, Szepetowski P, Hammadouche T, Vandenberghe A, Stewart CL, Grid D, Lévy N (2002) Homozygous defects in LMNA, encoding lamin $\mathrm{A} / \mathrm{C}$ nuclear-envelope proteins, cause autosomal recessive axonal 
neuropathy in human (Charcot-Marie-Tooth disorder type 2) and mouse. Am J Hum Genet 70:726-736.

De Sandre-Giovannoli A, Bernard R, Cau P, Navarro C, Amiel J, Boccaccio I, Lyonnet S, Stewart CL, Munnich A, Le Merrer M, Lévy N (2003) Lamin A truncation in Hutchinson-Gilford progeria. Science 300:2055.

DeChiara TM, Bowen DC, Valenzuela DM, Simmons MV, Poueymirou WT, Thomas S, Kinetz E, Compton DL, Rojas E, Park JS, Smith C, DiStefano PS, Glass DJ, Burden SJ, Yancopoulos GD (1996) The receptor tyrosine kinase MuSK is required for neuromuscular junction formation in vivo. Cell 85:501-512.

Deschenes MR, Roby MA, Eason MK, Harris MB (2010) Remodeling of the neuromuscular junction precedes sarcopenia related alterations in myofibers. Exp Gerontol 45:389-393.

Doherty TJ, Vandervoort AA, Brown WF (1993) Effects of ageing on the motor unit: a brief review. Can J Appl Physiol 18:331-358.

Dong XP, Li XM, Gao TM, Zhang EE, Feng GS, Xiong WC, Mei L (2006) Shp2 is dispensable in the formation and maintenance of the neuromuscular junction. Neurosignals 15:53-63.

Dong Z, Chen W, Chen C, Wang H, Cui W, TAN Z, Robinson H, Gao N, Luo B, Zhang L, Zhao K, Xiong W-C, Mei L (2020) CUL3 Deficiency Causes Social Deficits and Anxiety-like Behaviors by Impairing Excitation-Inhibition Balance through the Promotion of Cap-Dependent Translation. Neuron 105:475-490.e476.

Eguchi T, Tezuka T, Fukudome T, Watanabe Y, Sagara H, Yamanashi Y (2020) Overexpression of Dok-7 in skeletal muscle enhances neuromuscular transmission with structural alterations of neuromuscular junctions: implications in robustness of neuromuscular transmission. Biochem Biophys Res Commun 523:214-219.

Elmqvist D, Mattsson C, Heilbronn E, Lundh H, Libelius R (1977) Acetylcholine receptor protein. Neuromuscular transmission in immunized rabbits. Arch Neurol 34:7-11.

Eriksson M, Brown WT, Gordon LB, Glynn MW, Singer J, Scott L, Erdos MR, Robbins CM, Moses TY, Berglund P, Dutra A, Pak E, Durkin S, Csoka AB, Boehnke M, Glover TW, Collins FS (2003) Recurrent de novo point mutations in lamin A cause Hutchinson-Gilford progeria syndrome. Nature 423:293-298.

Fatt P, Katz B (1952) Spontaneous subthreshold activity at motor nerve endings. J Physiol 117:109-128.

Frock RL, Kudlow BA, Evans AM, Jameson SA, Hauschka SD, Kennedy BK (2006) Lamin A/C and emerin are critical for skeletal muscle satellite cell differentiation. Genes Dev 20:486-500.

Gautam M, Noakes PG, Mudd J, Nichol M, Chu GC, Sanes JR, Merlie JP (1995) Failure of postsynaptic specialization to develop at neuromuscular junctions of rapsyn-deficient mice. Nature 377:232-236.

Gautam M, Noakes PG, Moscoso L, Rupp F, Scheller RH, Merlie JP, Sanes JR (1996) Defective neuromuscular synaptogenesis in agrin-deficient mutant mice. Cell 85:525-535.

Grimby G, Saltin B (1983) The ageing muscle. Clin Physiol 3:209-218.

Grob D, Harvey AM (1953) Abnormalities in neuromuscular transmission, with special reference to myasthenia gravis. Am J Med 15:695-709.

Hesser BA, Henschel O, Witzemann V (2006) Synapse disassembly and formation of new synapses in postnatal muscle upon conditional inactivation of MuSK. Mol Cell Neurosci 31:470-480.

Hutchison CJ (2002) Lamins: building blocks or regulators of gene expression? Nat Rev Mol Cell Biol 3:848-858.

Jaworski A, Smith CL, Burden SJ (2007) GA-binding protein is dispensable for neuromuscular synapse formation and synapse-specific gene expression. Mol Cell Biol 27:5040-5046.

Kim D, Langmead B, Salzberg SL (2015) HISAT: a fast spliced aligner with low memory requirements. Nat Methods 12:357-360.

Kim N, Stiegler AL, Cameron TO, Hallock PT, Gomez AM, Huang JH, Hubbard SR, Dustin ML, Burden SJ (2008) Lrp4 is a receptor for agrin and forms a complex with MuSK. Cell 135:334-342.

Kim Y, Zheng Y (2013) Generation and characterization of a conditional deletion allele for Lmna in mice. Biochem Biophys Res Commun 440:8-13.

Knight D, Tolley LK, Kim DK, Lavidis NA, Noakes PG (2003) Functional analysis of neurotransmission at $\beta$-laminin deficient terminals. J Physiol 546:789-800.

LaRochelle WJ, Froehner SC (1986) Determination of the tissue distributions and relative concentrations of the postsynaptic $43-\mathrm{kDa}$ protein and the acetylcholine receptor in torpedo. J Biol Chem 261:5270-5274.
Li L, Cao Y, Wu H, Ye X, Zhu Z, Xing G, Shen C, Barik A, Zhang B, Xie X, Zhi W, Gan L, Su H, Xiong WC, Mei L (2016) Enzymatic activity of the scaffold protein rapsyn for synapse formation. Neuron 92:1007-1019.

Li L, Xiong WC, Mei L (2018) Neuromuscular junction formation, aging, and disorders. Annu Rev Physiol 80:159-188.

Li XM, Dong XP, Luo SW, Zhang B, Lee DH, Ting AKL, Neiswender H, Kim CH, Carpenter-Hyland E, Gao TM, Xiong WC, Mei L (2008) Retrograde regulation of motoneuron differentiation by muscle $\beta$-catenin. Nat Neurosci 11:262-268.

Li Y, Lee Y, Thompson WJ (2011) Changes in aging mouse neuromuscular junctions are explained by degeneration and regeneration of muscle fiber segments at the synapse. J Neurosci 31:14910-14919.

Luo S, Zhang B, Dong XP, Tao Y, Ting A, Zhou Z, Meixiong J, Luo J, Chiu FC, Xiong WC, Mei L (2008) HSP90 beta regulates rapsyn turnover and subsequent AChR cluster formation and maintenance. Neuron 60:97110.

Madisen L, Zwingman TA, Sunkin SM, Oh SW, Zariwala HA, Gu H, Ng LL, Palmiter RD, Hawrylycz MJ, Jones AR, Lein ES, Zeng H (2010) A robust and high-throughput Cre reporting and characterization system for the whole mouse brain. Nat Neurosci 13:133-140.

Meier T, Hauser DM, Chiquet M, Landmann L, Ruegg MA, Brenner HR (1997) Neural agrin induces ectopic postsynaptic specializations in innervated muscle fibers. J Neurosci 17:6534-6544.

Méjat A, Decostre V, Li J, Renou L, Kesari A, Hantaï D, Stewart CL, Xiao X, Hoffman E, Bonne G, Misteli T (2009) Lamin A/C-mediated neuromuscular junction defects in Emery-Dreifuss muscular dystrophy. J Cell Biol 184:31-44.

Merlie JP, Sanes JR (1985) Concentration of acetylcholine receptor mRNA in synaptic regions of adult muscle fibres. Nature 317:66-68.

Messi ML, Delbono O (2003) Target-derived trophic effect on skeletal muscle innervation in senescent mice. J Neurosci 23:1351-1359.

Miniou P, Tiziano D, Frugier T, Roblot N, Le Meur M, Melki J (1999) Gene targeting restricted to mouse striated muscle lineage. Nucleic Acids Res 27:e27.

Miyoshi S, Tezuka T, Arimura S, Tomono T, Okada T, Yamanashi Y (2017) DOK7 gene therapy enhances motor activity and life span in ALS model mice. EMBO Mol Med 9:880-889.

Mounkes L, Kozlov S, Burke B, Stewart CL (2003) The laminopathies: nuclear structure meets disease. Curr Opin Genet Dev 13:223-230.

Muscat GEO, Kedes L (1987) Multiple 5'-flanking regions of the human alpha-skeletal actin gene synergistically modulate muscle-specific expression. Mol Cell Biol 7:4089-4099.

Nishimune H, Sanes JR, Carlson SS (2004) A synaptic laminin-calcium channel interaction organizes active zones in motor nerve terminals. Nature 432:580-587.

Nishimune H, Valdez G, Jarad G, Moulson CL, Müller U, Miner JH, Sanes JR (2008) Laminins promote postsynaptic maturation by an autocrine mechanism at the neuromuscular junction. J Cell Biol 182:1201-1215.

Noakes PG, Gautam M, Mudd J, Sanes JR, Merlie JP (1995) Aberrant differentiation of neuromuscular junctions in mice lacking s-laminin/laminin beta 2. Nature 374:258-262.

Novelli G, D'Apice MR (2003) The strange case of the "lumper" lamin A/C gene and human premature ageing. Trends Mol Med 9:370-375.

Patten SA, Aggad D, Martinez J, Tremblay E, Petrillo J, Armstrong GA, La Fontaine A, Maios C, Liao M, Ciura S, Wen XY, Rafuse V, Ichida J, Zinman L, Julien JP, Kabashi E, Robitaille R, Korngut L, Parker JA, Drapeau P (2017) Neuroleptics as therapeutic compounds stabilizing neuromuscular transmission in amyotrophic lateral sclerosis. JCI Insight 2:e97152.

Pérez-García MJ, Burden SJ (2012) Increasing MuSK activity delays denervation and improves motor function in ALS mice. Cell Rep 2:497-502.

Robinson MD, McCarthy DJ, Smyth GK (2010) edgeR: a bioconductor package for differential expression analysis of digital gene expression data. Bioinformatics 26:139-140.

Roos MR, Rice CL, Vandervoort AA (1997) Age-related changes in motor unit function. Muscle Nerve 20:679-690.

Rowan SL, Rygiel K, Purves-Smith FM, Solbak NM, Turnbull DM, Hepple RT (2012) Denervation causes fiber atrophy and myosin heavy chain coexpression in senescent skeletal muscle. PLoS One 7:e29082.

Samuel MA, Valdez G, Tapia JC, Lichtman JW, Sanes JR (2012) Agrin and synaptic laminin are required to maintain adult neuromuscular junctions. PLoS One 7:e46663. 
Sanes JR, Lichtman JW (2001) Induction, assembly, maturation and maintenance of a postsynaptic apparatus. Nat Rev Neurosci 2:791-805.

Scaffidi P, Misteli T (2006) Lamin A-dependent nuclear defects in human aging. Science 312:1059-1063.

Schaeffer L, de Kerchove d'Exaerde A, Changeux JP (2001) Targeting transcription to the neuromuscular synapse. Neuron 31:15-22.

Schwander M, Shirasaki R, Pfaff SL, Müller U (2004) $\beta 1$ integrins in muscle, but not in motor neurons, are required for skeletal muscle innervation. J Neurosci 24:8181-8191.

Shen C, Lu Y, Zhang B, Figueiredo D, Bean J, Jung J, Wu H, Barik A, Yin DM, Xiong WC, Mei L (2013) Antibodies against low-density lipoprotein receptor-related protein 4 induce myasthenia gravis. J Clin Invest 123:5190-5202.

Shen C, Li L, Zhao K, Bai L, Wang A, Shu X, Xiao Y, Zhang J, Zhang K, Hui T, Chen W, Zhang B, Hsu W, Xiong W-C, Mei L (2018) Motoneuron Wnts regulate neuromuscular junction development. Elife 7:e34625.

Sullivan T, Escalante-Alcalde D, Bhatt H, Anver M, Bhat N, Nagashima K, Stewart CL, Burke B (1999) Loss of A-type lamin expression compromises nuclear envelope integrity leading to muscular dystrophy. J Cell Biol 147:913-920.

Valdez G, Tapia JC, Kang H, Clemenson GD, Gage FH, Lichtman JW, Sanes JR (2010) Attenuation of age-related changes in mouse neuromuscular synapses by caloric restriction and exercise. Proc Natl Acad Sci USA 107:14863-14868.

Walker JH, Boustead CM, Witzemann V (1984) The 43-K protein, v1, associated with acetylcholine receptor containing membrane fragments is an actin-binding protein. EMBO J 3:2287-2290.

Weatherbee SD, Anderson KV, Niswander LA (2006) LDL-receptor-related protein 4 is crucial for formation of the neuromuscular junction. Development 133:4993-5000.

Wickham H (2016) ggplot2: elegant graphics for data analysis. New York: Springer.
Willadt S, Nash M, Slater CR (2016) Age-related fragmentation of the motor endplate is not associated with impaired neuromuscular transmission in the mouse diaphragm. Sci Rep 6:24849.

Wu H, Xiong WC, Mei L (2010) To build a synapse: signaling pathways in neuromuscular junction assembly. Development 137:1017-1033.

Wu H, Lu Y, Shen C, Patel N, Gan L, Xiong WC, Mei L (2012a) Distinct roles of muscle and motoneuron LRP4 in neuromuscular junction formation. Neuron 75:94-107.

Wu H, Lu Y, Barik A, Joseph A, Taketo MM, Xiong W-C, Mei L (2012b) $\beta$-Catenin gain of function in muscles impairs neuromuscular junction formation. Development 139:2392-2404.

Xing G, Jing H, Zhang L, Cao Y, Li L, Zhao K, Dong Z, Chen W, Wang H, Cao R, Xiong W-C, Mei L (2019) A mechanism in agrin signaling revealed by a prevalent Rapsyn mutation in congenital myasthenic syndrome. Elife 8:e49180.

Yang X, Arber S, William C, Li L, Tanabe Y, Jessell TM, Birchmeier C, Burden SJ (2001) Patterning of muscle acetylcholine receptor gene expression in the absence of motor innervation. Neuron 30:399410

Yu GC, Wang LG, Han YY, He QY (2012) clusterProfiler: an R package for comparing biological themes among gene clusters. OMICS 16:284-287.

Zhang B, Luo S, Wang Q, Suzuki T, Xiong WC, Mei L (2008) LRP4 serves as a coreceptor of agrin. Neuron 60:285-297.

Zhao K, Shen C, Lu Y, Huang Z, Li L, Rand CD, Pan J, Sun XD, Tan Z, Wang H, Xing G, Cao Y, Hu G, Zhou J, Xiong WC, Mei L (2017) Muscle yap is a regulator of neuromuscular junction formation and regeneration. J Neurosci 37:3465-3477.

Zhao K, Shen C, Li L, Wu H, Xing G, Dong Z, Jing H, Chen W, Zhang H, Tan Z, Pan J, Xiong L, Wang H, Cui W, Sun XD, Li S, Huang X, Xiong WC, Mei L (2018) Sarcoglycan alpha mitigates neuromuscular junction decline in aged mice by stabilizing LRP4. J Neurosci 38:8860-8873.

Zong Y, Zhang B, Gu S, Lee K, Zhou J, Yao G, Figueiredo D, Perry K, Mei L, Jin R (2012) Structural basis of agrin-LRP4-MuSK signaling. Genes Dev 26:247-258. 